\title{
SYNTHESIS AND ASSIMILATION SYSTEMS - ESSENTIAL ADJUNCTS TO THE GLOBAL OCEAN OBSERVING SYSTEM
}

Michele M. Rienecker ${ }^{(1)}$, Toshiyuki Awaji ${ }^{(2)}$, Magdalena Balmaseda ${ }^{(3)}$, Bernard Barnier ${ }^{(4)}$, David Behringer ${ }^{(5)}$, Mike Bell $^{(6)}$, Mark Bourassa ${ }^{(7)}$, Pierre Brasseur ${ }^{(8)}$, Lars-Anders Breivik ${ }^{(9)}$, James Carton ${ }^{(10)}$, James Cummings ${ }^{(11)}$, Eric Dombrowsky $^{(12)}$, Chris Fairall ${ }^{(13)}$, Nicolas Ferry ${ }^{(14)}$, Gael Forget ${ }^{(15)}$, Howard Freeland ${ }^{(16)}$, Watson Gregg ${ }^{(17)}$, Stephen M. Griffies ${ }^{(18)}$, Keith Haines ${ }^{(19)}$, D. Edward Harrison ${ }^{(20)}$, Patrick Heimbach ${ }^{(21)}$, Masafumi Kamachi ${ }^{(22)}$, Elizabeth Kent $^{(23)}$, Tong Lee ${ }^{(24)}$, Pierre-Yves Le Traon ${ }^{(25)}$, Michael McPhaden ${ }^{(26)}$, Matthew J. Martin ${ }^{(27)}$, Peter Oke ${ }^{(28)}$, Matthew D. Palmer ${ }^{(29)}$, Elisabeth Remy ${ }^{(30)}$, Anthony Rosati ${ }^{(31)}$, Andreas Schiller ${ }^{(32)}$, Doug M. Smith ${ }^{(33)}$, Detlef Stammer ${ }^{(34)}$, Nozomi Sugiura ${ }^{(35)}$, Kevin E. Trenberth ${ }^{(36)}$, Yan Xue ${ }^{(37)}$

${ }^{(1)}$ NASA/GFSC, Global Modeling and Assimilation Office, Greenbelt, MD 20771, USA, Email: Michele.Rienecker@nasa.gov

${ }^{(2)}$ Department of Geophysics, Kyoto University, Kyoto 606 8502, Japan, Email: awaji@kugi.kyoto-u.ac.jp

${ }^{(3)}$ ECMWF, Shinfield Park, Reading RG2 9AX, UK, Email: Magdalena.Balmaseda@ecmwf.int

${ }^{(4)}$ Laboratoire des Écoulements Géophysiques et Industriels, CNRS, BP53, 38041 Grenoble Cedex 9, France, Email: Bernard.Barnier@hmg.inpg.fr

${ }^{(5)}$ NOAA/NCEP, 5200 Auth Rd, Camp Springs, MD 20746, USA, Email: David.Behringer@noaa.gov

${ }^{(6)}$ National Centre for Ocean Forecasting, Met Office, FitzRoy Road, Exeter, Devon, EXI 3PB, UK, Email: Mike.Bell@metoffice.gov.uk

(7) COAPS, Florida State University, Tallahassee, FL, 32306-2840, USA, Email: Bourassa@ coaps.fsu.edu

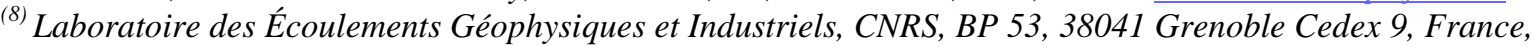
Email:Pierre.Brasseur@hmg.inpg.fr

${ }^{(9)}$ Norwegian Meteorological Institute, P.O. Box 43 Blindern N-0313 Oslo, Norway, Email: l.a.breivik@met.no

${ }^{(10)}$ Department of Atmospheric and Oceanic Science, University of Maryland, College Park, MD 20742, USA, Email: carton@atmos.umd.edu

${ }^{(11)}$ Naval Research Laboratory, 7 Grace Hopper Ave., Monterey, CA, 93943 USA, Email: James.Cummings@nrlmry.navy.mil

${ }^{(12)}$ MERCATOR OCEAN, 8-10 Rue Hermes, 31520 Ramonville, St Agne, France, Email: Eric.Dombrowsky@mercator-ocean.fr

${ }^{(13)}$ NOAA/ESRL, 325 Broadway, R/PSD3 Boulder, CO 80305, USA, Email: Chris.Fairall@noaa.gov (14) MERCATOR OCEAN, 8-10 Rue Hermes, 31520 Ramonville, St Agne, France, Email: nferry@mercator-ocean.fr

${ }^{(15)}$ Dept. of Earth, Atmospheric, and Planetary Sciences. Massachusetts Institute of Technology, Cambridge, MA 02139-4307USA,Email: gforget@mit.edu

${ }^{(16)}$ Fisheries and Oceans Canada, Institute of Ocean Sciences, Sidney, BC, V8L 4B2, Canada, Email: howard.freeland@dfo-mpo.gc.ca

${ }^{(17)}$ NASA/GFSC, Global Modeling and Assimilation Office, Greenbelt, MD 20771, USA, Email: watson.w.gregg@nasa.gov

${ }^{(18)}$ NOAA/GFDL, P.O. Box 308, Princeton, NJ 08542, USA, Email: Stephen.Griffies @ noaa.gov

${ }^{(19)}$ Reading e-Science Centre, 3 Earley Gate, Reading University, Reading RG6 6AL, UK, Email: kh@mail.nerc-essc.ac.uk

${ }^{(20)}$ NOAA/R/PMEL, 7600 Sand Point Way NE, Seattle, WA 98115, USA, Email: D.E.Harrison@noaa.gov

${ }^{(21)}$ Dept. of Earth, Atmospheric, and Planetary Sciences. Massachusetts Institute of Technology, Cambridge, MA 02139-4307 USA, Email: heimbach@mit.edu

${ }^{(22)}$ Meteorological Research Institute, 1-1 Nagamine, Tsukuba 305-0052, Japan, Email: mkamachi@mri-jma.go.jp

${ }^{(23)}$ Ocean Observing and Climate, National Oceanography Centre, Southampton, SO14 3ZH, UK, Email: eck@noc.soton.ac.uk

${ }^{(24)}$ NASA /JPL, 4800 Oak Grove Dr., Pasadena, CA 91109, Email: Tong.Lee@jpl.nasa.gov

${ }^{(25)}$ IFREMER, Centre de Brest, Technopôle de Brest Iroise, B.P. 70, 29280, Plouzané, France, Email: pierre.yves.le.traon@ifremer.fr

${ }^{(26)}$ NOAA/R/PMEL, 7600 Sand Point Way NE, Seattle, WA 98115, USA, Email: Michael.J.Mcphaden@noaa.gov

${ }^{(27)}$ Met Office, FitzRoy Road, Exeter, Devon, EX1 3PB, UK, Email: Matthew.Martin@metoffice.gov.uk

${ }^{(28)}$ CAWCR, GPO Box 1538, Hobart TAS 7001, Australia, Email: Peter.Oke@csiro.au

${ }^{(29)}$ Met Office, FitzRoy Road, Exeter, Devon, EX1 3PB, UK, Email: Matthew.Palmer@metoffice.gov.uk

${ }^{(30)}$ MERCATOR OCEAN, 8-10 Rue Hermes, 31520 Ramonville, St Agne, France,

Email: Elisabeth.Remy@mercator-ocean.fr

${ }^{(31)}$ NOAA/GFDL, P.O. Box 308, Princeton, NJ 08542, USA, Email: Tony.Rosati@noaa.gov

${ }^{(32)}$ CAWCR, GPO Box 1538, Hobart TAS 7001, Australia, Email: Andreas.Schiller@csiro.au 


\section{${ }^{(33)}$ Met Office, FitzRoy Road, Exeter, Devon, EX1 3PB, UK, Email: Doug.Smith@metoffice.gov.uk ${ }^{(34)}$ KlimaCampus Universität Hamburg, Bundesstr. 53, 20146 Hamburg, Germany,_Email: Detlef.Stammer@zmaw.de ${ }^{(35)}$ Data Research Center for Marine-Earth Sciences, JAMSTEC, 3173-25 Showa-machi, Kanazawa-ku Yokohama 236-0001, Japan, Email: nsugiura@jamstec.go.jp \\ ${ }^{(36)}$ NCAR, P. O. Box 3000, Boulder, CO 80307, USA, Email: trenbert@ucar.edu ${ }^{(37)}$ NOAA/NCEP, 5200 Auth Rd, Camp Springs, MD 20746, USA, Email: YanXue@noaa.gov}

\begin{abstract}
Ocean assimilation systems synthesize diverse in situ and satellite data streams into four-dimensional state estimates by combining the various observations with the model. Assimilation is particularly important for the ocean where subsurface observations, even today, are sparse and intermittent compared with the scales needed to represent ocean variability and where satellites only sense the surface.
\end{abstract}

Developments in assimilation and in the observing system have advanced our understanding and prediction of ocean variations at mesoscale and climate scales. Use of these systems for assessing the observing system helps identify the strengths of each observation type. Results indicate that the ocean remains under-sampled and that further improvements in the observing system are needed.

Prospects for future advances lie in improved models and better estimates of error statistics for both models and observations. Future developments will be increasingly towards consistent analyses across components of the Earth system. However, even today ocean synthesis and assimilation systems are providing products that are useful for many applications and should be considered an integral part of the global ocean observing and information system.

\section{INTRODUCTION}

In environmental data assimilation, models are used to synthesize diverse in situ and satellite data streams into a single product (an analysis or state estimate), combining the various observations with the model, each according to its strengths. Assimilation systems are particularly important for the ocean where subsurface observations, even today, are sparse and intermittent compared with the scales needed to represent ocean variability and where satellites only sense the surface. The resulting analysis provides an integrated view of the information from the various observations as well as derived estimates of unobserved quantities such as currents, property transport, overturning circulations, etc.

For ocean data assimilation, international cooperation under the auspices of the Global Ocean Data Assimilation Experiment (GODAE) had an indelible impact on the routine generation of synthesis products and the outreach to user communities [1]. GODAE not only demonstrated the feasibility of global ocean data assimilation but also made important contributions to the establishment of an effective and efficient infrastructure for global operational oceanography that includes the required observing systems, data assembly and processing centres, modelling and data assimilation centres, and data and product servers.

Many successful applications from GODAE systems are highlighted in [2]: monitoring and prediction of marine pollution, forecasts for safety and effectiveness of operations at sea, information and tactical decision aids to assist Naval operations, operational use of upper ocean heat content information to forecast the intensity of tropical cyclones, and ocean initialization of coupled climate forecast systems. Several examples of the use of ocean current forecasts by national coast guard agencies for safety applications at sea, including drift calculations for search and rescue, iceberg drift calculations, ice cover prediction, and safety of offshore operations are provided by [3]. Their conclusion is that improved GODAE OceanView analyses will help save fuel, increase efficiency, and improve safety. Reference [4] provides several examples of the use of GODAE operational ocean data products by oil spill monitoring and prediction providers around the world. Benefits of using GODAE products in oil spill modeling include: improved prediction accuracy, particularly when used as nesting data for local high-resolution ocean models; global coverage, whereby any oil spill model can, in principle, be applied anywhere in the world ocean; and facilitating alternative forecasts for an incident from other oil spill models.

Ocean assimilation has also demonstrated its utility for climate applications. In particular, ocean analyses have been undertaken for the initialization of seasonal forecasts since the mid-1990's (e.g., [5], [6] and [7]). Now, several operational centres around the world issue routine seasonal forecasts from coupled oceanatmosphere models initialized from ocean and atmospheric analyses ([8]). Historical ocean reanalyses and the associated forecasts provide information for forecast calibration and skill assessment. These products also offer a means for monitoring the state of Earth's climate, providing information on precursors to climate variations such as the build up of warm water in the western equatorial Pacific prior to an El Niño event (e.g., [9]).

Advances in assimilation systems for the ocean, the organization of the archive of historical in situ data and the onset of the era of high quality altimetry, and, most 
importantly, the availability of long atmospheric reanalyses spurred the generation of historical ocean reanalyses for the study of climate variability (e.g., [5], [10], [11], inter alia). Today, a suite of global ocean climate synthesis products is available, some extending for a duration of 50 years, others focusing on the data rich period of the ocean satellite era, roughly from 1993 to the present. The number of studies using these products for oceanographic and climate-related studies covers a wide range of topics, as highlighted in [12]: ocean circulation studies, sea level variability, watermass pathways, estimation of surface fluxes and river runoff, and interannual and decadal variability of the upper-ocean and heat content. They have also been applied to research in other disciplines such as biogeochemistry and geodesy.

Increasingly, models and assimilation systems are being used to provide information about the current observing system and to help in the design plans for new observations. Whether as a user of observations or a contributor to evaluation of the observing system, ocean data assimilation systems are now an integral part of the global ocean observing and information system.

This paper gives a brief summary of synthesis and assimilation systems, with a focus on the observing system. Section 2 provides a brief overview of the state of the art of ocean data assimilation, and Sect. 3 the challenges being faced particularly for ocean syntheses of the climate record. Section 4 provides a view of emerging developments and the path forward for the ocean data assimilation as an integral part of the global ocean observing and information system. The paper concludes with some recommendations for both observations and assimilation systems in Sect. 5.

\section{THE CURRENT GLOBAL SYNTHESIS EFFORTS}

An ocean analysis is obtained by minimizing the scalar cost function

$$
\begin{aligned}
J= & \frac{1}{2}\left(\mathbf{x}-\mathbf{x}^{b}\right)^{\mathrm{T}} \mathbf{P}^{-1}\left(\mathbf{x}-\mathbf{x}^{b}\right)+ \\
& \frac{1}{2}(h(\mathbf{x})-\mathbf{y})^{\mathrm{T}} \mathbf{R}^{-1}(h(\mathbf{x})-\mathbf{y})+J_{c}
\end{aligned}
$$

with respect to the control vector, $\mathbf{x}$, which is usually the state vector (temperature, salinity, currents, sea level, sea-ice concentration, tracers, phytoplankton, nutrient concentrations, etc.) or related variables. The vector $\mathbf{x}^{b}$ represents the background or prior estimate of $\mathbf{x}$ from the model integration, and $\mathbf{P}$ is its expected error covariance. The vector $\mathbf{y}$ contains the available observations, the operator $h(\mathbf{x})$ simulates these observations from $\mathbf{x}$, and $\mathbf{R}$ is the expected covariance of the instrument plus representativeness errors associated with the observations. The superscript $\mathrm{T}$ denotes the transpose operation. The term $J_{\mathrm{c}}$ represents constraints that are applied in some situations, such as the preservation of model water masses or a penalty for negative nutrient concentrations.

A variety of methods are used to perform ocean state estimation on a routine basis, ranging from relatively simple and computationally efficient sequential or filter methods such as optimal interpolation (OI), asymptotic Kalman filters, and the 3-dimensional variational (3DVar) method, to sophisticated and computationally intensive methods, including ensemble methods that provide state-dependent estimates of the multivariate background error covariances, Kalman smoothers, and the four-dimensional variational (4DVar) method.

Reference [13] provides an overview of the assimilation methods used by many GODAE systems and [14] provides an overview and comparison of twelve of the systems developed/operated during GODAE. Most realtime operational oceanography systems have $1 / 10^{\circ}$ or finer horizontal grid spacing, have a global capability, and make use of community ocean models (e.g., the HYbrid Coordinate Ocean Model (HYCOM), Version 4 of the Modular Ocean Model (MOM4), or the Nucleus for European Modelling of the Ocean (NEMO)). References [8] and [12] provide information on many of the systems used for climate applications. Because of their need to synthesize the historical data stream, climate-focused systems tend to have coarser resolution, from about $0.25^{\circ}$ to about $2^{\circ}$, usually with some equatorial refinement. Surface fluxes, which drive the ocean models, come from various sources, especially from atmospheric reanalyses.

Many data types are routinely synthesized to produce ocean state estimates. The most commonly used are seasurface height (SSH) anomalies from altimeters (e.g., TOPEX/Poseidon and JASON-1, -2 [15]), in situ temperature (T) profiles from XBTs/CTDs (Expendable Bathythermographs/Conductivity-Temperature-Depths) [16 and 17], the global tropical moored buoy array [18], and Argo (Array for Real-time Geostrophic Oceanography) [19] and in situ salinity (S) profiles from Argo. Sea surface temperature (SST) estimates (e.g., [20], [21]) are either assimilated directly or used as a surface boundary condition. Salinity data from CTDs and velocity data from current meters and acoustic Doppler current profilers (ADCPs) are usually used for validation. Gravity measurements from the Gravity Recovery and Climate Experiment (GRACE) and the newly launched Gravity field and steady-state Ocean circulation Explorer (GOCE) provide estimates of the geoid for use with altimetry as well as derived bottom pressure estimates (e.g., [22] and [23]).

Many aspects of the quality of the ocean analyses have been presented in papers documenting the various 
systems as well as in papers presented at the GODAE Final Symposium. As an example of the latter, [24] presents validation and intercomparison studies, focused on operational products, conducted through GODAE. The validation was approached through standardized output and a set of detailed diagnostic metrics. The analyses of the general ocean circulation were shown to be in agreement with known patterns. Day-to-day representations of eddy fields varied, but, statistically, the ocean variability was similar among the systems.

On climate timescales, many assimilation groups in the U.S., Europe, and Japan participated in a cooperative effort through the World Climate Research Programme's (WCRP's) Climate Variability and Predictability Project (CLIVAR) Global Synthesis and Observations Panel (GSOP) and GODAE to compare a suite of diagnostic quantities derived from the different ocean reanalyses and also from observations. Some results are presented below and in [25]. More details are at http://www.clivar.org/organization/gsop/gsop.php.

Here we focus on the interplay between the analyses and observations and how ocean data assimilation can inform decisions regarding investments in the Global Ocean Observing System (GOOS).
Various studies have shown that different data types provide complementary information from the GOOS. Reference [26] undertook analyses of the observing system for mesoscale applications (see Sect. 4.2). They infer that all observation types are required for constraining mesoscale circulation models. An example from climate analyses is that from the ECCO group (Estimating the Circulation and Climate of the Ocean, see [27]) who incrementally added different data types to an ECCO synthesis for 2006. Figure 1 shows the differences in root mean square (RMS) variability of the global meridional overturning circulation from their study as different data sets are added. The results imply that overturning uncertainties would exceed $3 \mathrm{~Sv}$ in the absence of the modern observing capabilities. While the specific value may be particular to this experiment, uncertainties of at least this magnitude are likely to prevail in state estimates prior to the emergence of modern observing capabilities in the 1990's. The other panels show the impact of individual data sets. Not surprisingly, the stronger constraints on the overturning circulation come from altimetry and the in situ data (mostly Argo), while SST data provides a weaker constraint.

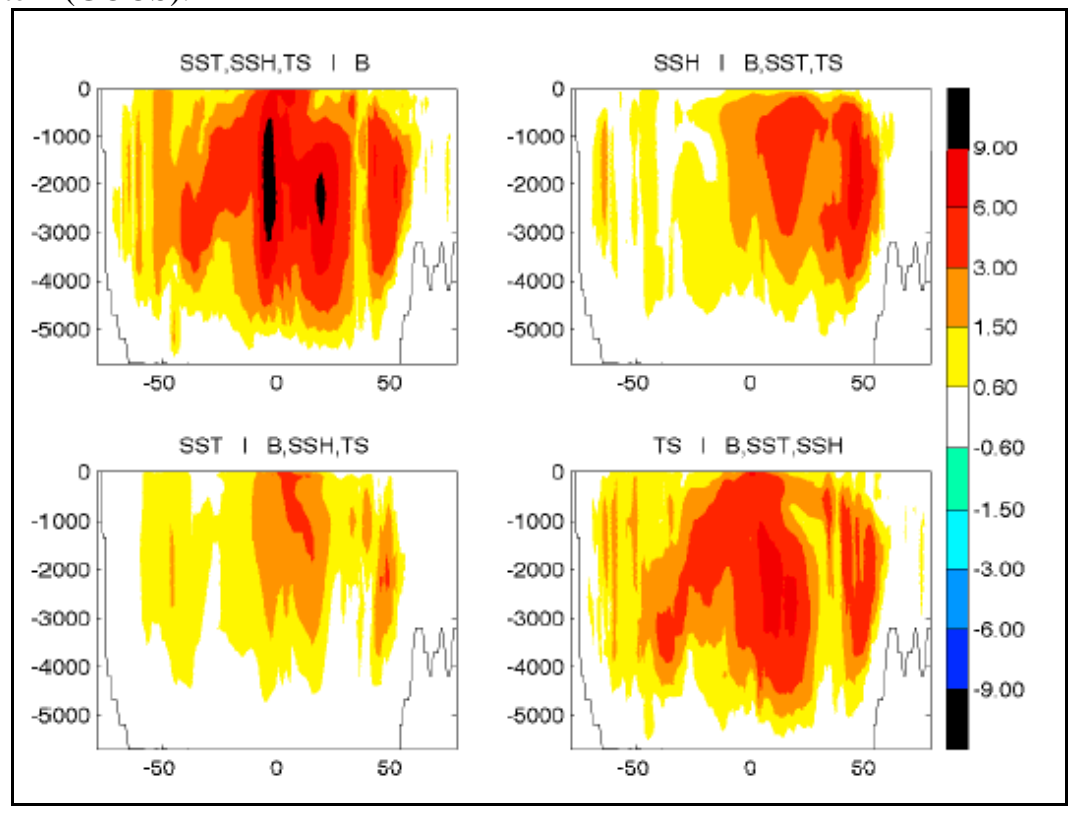

Figure 1. The impact of the modern GOOS on the global meridional overturning circulation (in Sv) from the ECCO synthesis [27]. The panels show RMS variability differences between ocean state estimates, based on bi-weekly averaged fields over the year 2006. Top left: the impact of jointly adding SST, SSH and in situ (T, S) data to a baseline estimate consisting only of hydrographic climatology. Top right, bottom left, bottom right: the impact of adding, respectively, $S S H, S S T$, and in situ $(T, S)$ data individually. 
Even the most recent atmospheric reanalyses provide different estimates of many aspects of the atmosphere's climate, particularly in the unconstrained variables such as precipitation and cloud properties. This is also the case for the different ocean state estimates: the underlying models and assimilation approaches differ, the weights (prior background and observation error covariances) given to observations and models differ, as do the data selections. The atmospheric forcing used also often differs. Of course, one expects that the largest differences between state estimates would occur in times of fewer observations if different surface forcing is applied (see Sect. 3.3) and the state estimates in the deeper ocean are still influenced by the initial states.

Depending on the application, a more reliable estimate of ocean climate variability may lie in multi-model ensemble approaches [25]. To proceed with this, one needs detailed error estimates for the estimated states, something that is difficult to obtain with most of the current assimilation implementations. Nevertheless, an important step toward improved estimates of the timevarying ocean state and its transport properties is to understand the uncertainties in each estimate, or at least the differences between different analysis products. Analysis intercomparisons, such as those from GSOP and GODAE help identify commonalities (confidence) and differences (uncertainty) in the products. They also help identify how or when observations constrain the estimation effectively.

As one of the outcomes of the GSOP intercomparison, [25] compares the variability in state estimates from multi-decadal syntheses ([11], [28], [29], [30], [31] [32], [33], [34], [35], [36] and [37]). There is a large spread in the various estimates of some quantities such as global upper ocean heat and freshwater content (Fig. 2), with an even wider spread in transport estimates (not shown). The spread is, to some extent, due to different approaches or underlying data sets. However, it is somewhat surprising that the spread increases toward the end of the data record characterized by the largest number of observations. Reference [25] shows more detail, with estimates in the individual basins. The agreement in heat content is much better in the wellobserved Atlantic Ocean (Fig. 2). The spread in freshwater content variability between all estimates is very large, suggesting a general problem in determining the salt content from current observations. This affects estimates of many climate indices, including global sea level rise.

Historical ocean state estimates rely on conventional ocean observations such as XBTs. It was shown recently that XBT data are contaminated by previously undetected errors in the assumed drop rate [38]. Several new data-only analyses have been made of the ocean heat content based upon corrected XBT fall rates and other adjustments to the basic data. These updated analyses tend to remove a lot of decadal variability ([30], [39], [40] and [41]). The estimate from [30] is included in the upper panel of Fig. 2, whereas none of the assimilation products included corrections to the data. Continued efforts are needed to address observational biases and, as a corollary, continued efforts are needed to improve ocean reanalyses by using the updated observation databases.

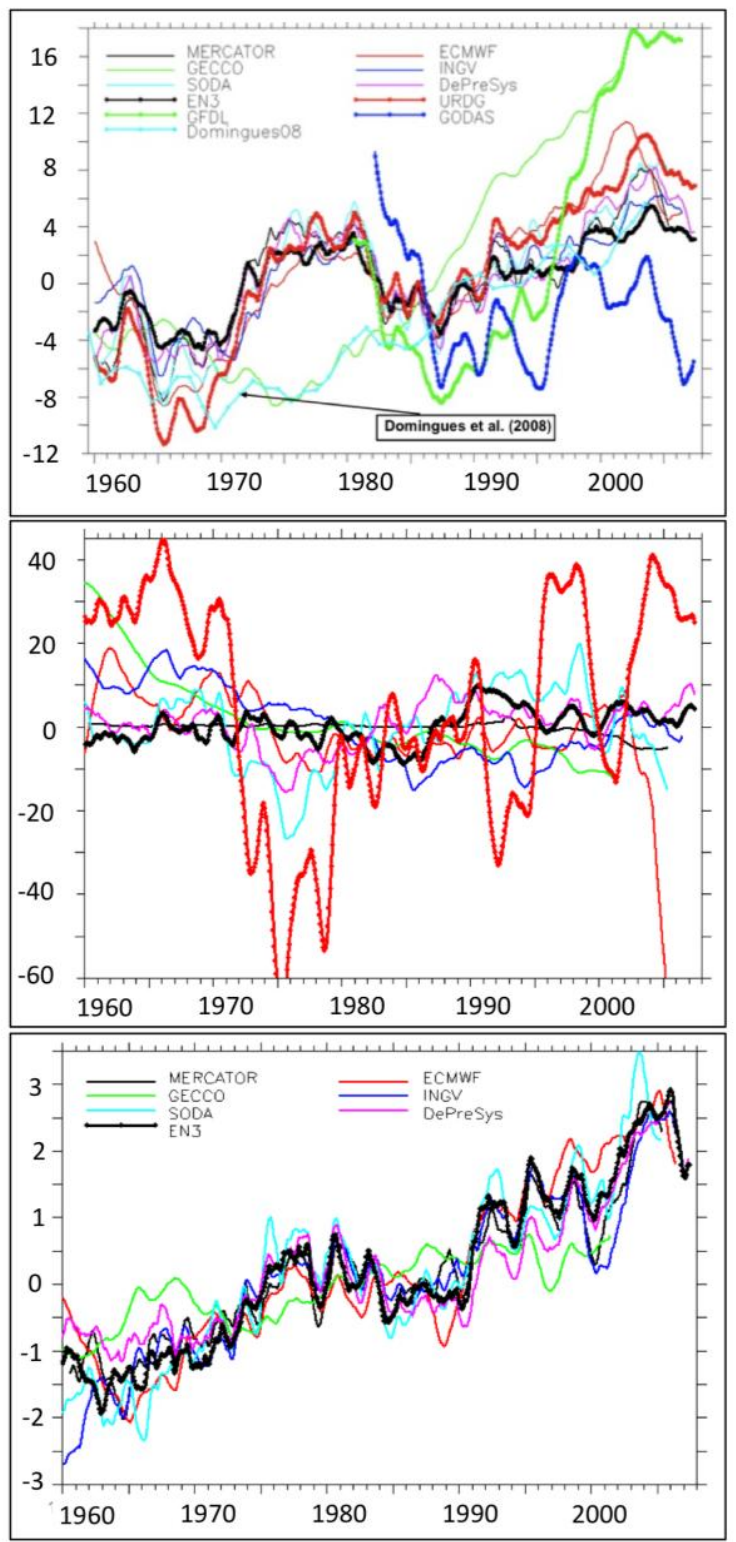

Figure 2. Global changes in heat content in the upper $700 \mathrm{~m}\left(10^{22} \mathrm{~J}\right.$, top panel) and freshwater content (cm, middle panel). Note that the Domingues heat content curve uses XBT data adjusted to compensate for fall-rate equation errors [30]. Bottom panel: Changes in heat content in the upper $700 \mathrm{~m}$ of the North Atlantic. From [25]. 


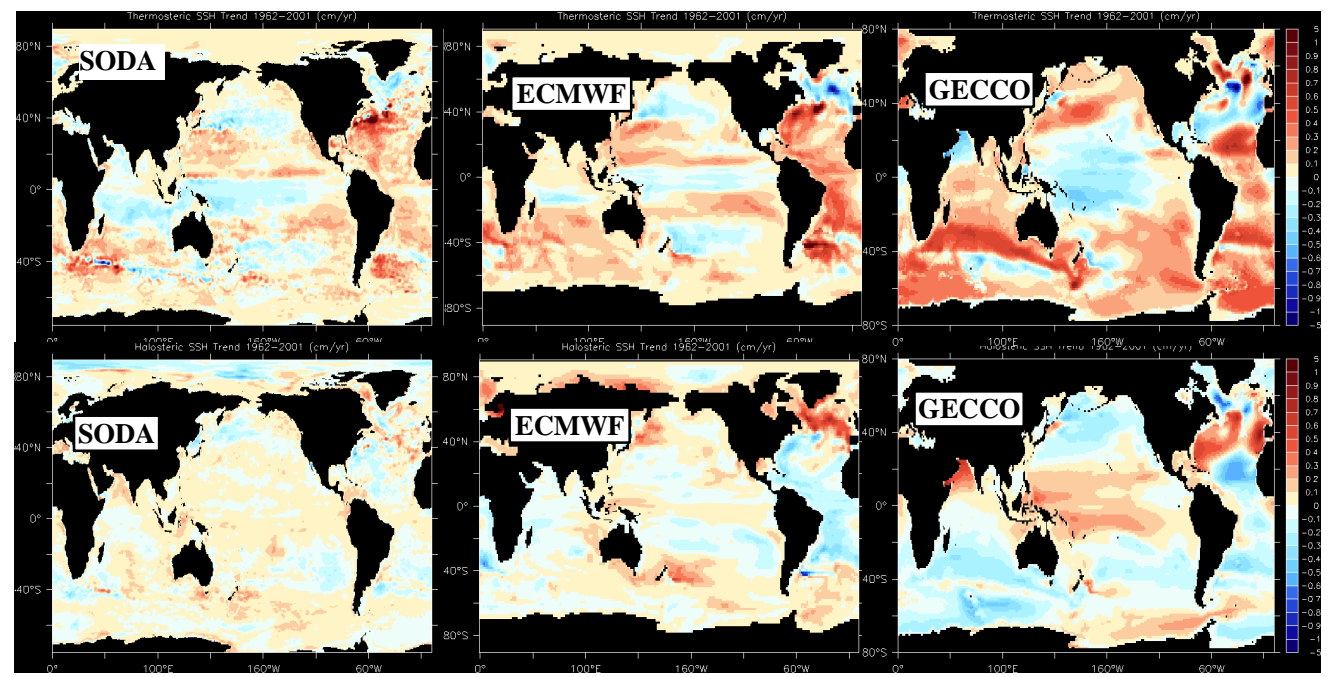

Figure 3 Estimates of local thermosteric (upper) and halosteric (lower) SSH trends over the period 1962 - 2001 from three estimates representing the spread in results from [25]. The SODA analysis is the left-hand column; the ECMWF (European Centre for Medium-Range Weather Forecasts) analysis is the centre column; the GECCO analysis is the right-hand column.

Sea level, or SSH, is an important climate variable whose variations have enormous impact on coastal communities. Fig. 3 shows three synthesis estimates of local thermosteric and halosteric SSH changes over the period from 1962 to 2001, representing the spread from the syntheses presented in [25]. The Simple Ocean Data Assimilation (SODA) [11] uses in situ profiles to correct the model's T/S structure locally in space and time. Altimetry is projected on synthetic T/S changes and only the latter are used as constraints. The results from the German partner of the ECCO efforts (GECCO) [32] represent the adjoint-family of approaches. Also shown are results from the European Centre for Medium-range Weather Forecasts (ECMWF) system [28], which is tuned to improve seasonal-to-interannual (SI) climate forecasts.

Estimated trends over the entire 40-year period from these three products differ substantially, especially between SODA and GECCO. Over large parts of the world ocean, GECCO results suggest that SSH changes induced by heat content changes and changes in salinity counterbalance to some extent. A counter balance is less visible in the SODA analysis. Again, these estimates are from analyses that did not use corrected XBT data.

In the more recent years when altimeter data have been assimilated (1992-2001), large-scale trends in the thermosteric $\mathrm{SSH}$ are in much better agreement in all three estimates (see [25]). Halosteric estimates also tend to converge but substantial differences remain, e.g., in the subpolar North Atlantic. Interestingly, the highresolution simulation (no assimilation) by [42] shows similar regional patterns for the trend over this recent decade. They find that taking salinity variations into account in the computation of steric sea level improves the comparison with observed regional sea level trend by $15 \%$ in RMS difference. The simulation indicates that regional sea level changes from 1993 to 2001 result more from changes in the ocean circulation than in atmospheric heat and water fluxes. In contrast, [32] infers that surface heat and freshwater fluxes contribute significantly (up to 50\%) to sea level trends over that period, especially in the northern hemisphere and the Antarctic Circumpolar Current region.

Understanding the differences between the analysis products and making further improvements in assimilation capabilities may require a concerted comparison effort wherein runs are undertaken with the same data and forcing and the analysis diagnostics are expanded to look at innovations and the details of data impacts. What is clear is that the salinity estimation and surface forcing both impact the inferences made about ocean climate variability and also prediction skill [8] using ocean synthesis products.

\section{CHALLENGES}

Perhaps the two greatest challenges for ocean data synthesis as a climate data record are the historical data themselves and the ability to make uncertainty estimates for the synthesis products. With the former, the severe under-sampling of the water column and of most regions of the ocean in the early periods, the issues of 
biases/uncertainties in air-sea fluxes (e.g., [43] and [44]) and model biases [45] take on greater importance.

\subsection{The Global Ocean Observing System}

Along with the view from [25] and [46], [47] provides another view of estimated trends in ocean temperature and issues faced by the climate community because of the uneven observational coverage in both space and time. They find that the estimated 50-year trends over most of the ocean are not significant at the $90 \%$ confidence level (CL). In fact, at $50 \mathrm{~m}$, only $30 \%$ of the ocean has a statistically significant trend with $90 \%$ CL, and the percentage decreases significantly with increasing depth. They suggest that upper ocean heat content estimates and trends may be substantially more uncertain than has yet been acknowledged and that further exploration of uncertainties is needed.

Some of the issues with data distribution are obvious from Fig. 4, showing the non-stationarity of the observing system, the under sampling of the deeper ocean even in the last two decades, and the decline of the in situ observing system in the marginal seas. The apparent horizontal strata reflect the successive influence of 450-m XBTs, 750-m XBTs, 500-m tropical moored buoys and 1000-m and 2000-m Argo floats. The importance of Argo to the ocean observing system is obvious [19]. The sampling situation is markedly worse for salinity observations (not shown), and the importance of Argo is magnified (e.g., Fig. 6 below). However, Argo does not currently help in observing the marginal seas, so an alternative, such as gliders [48] or reviving the XBT network, is needed to address the observing system decline there.

These changes in the GOOS over time have an impact on estimates not only of trends but also of decadal variability even when the estimates are made through assimilation of the historical record. The changes also impact the ability to confidently assess and calibrate seasonal climate forecast skill.

One source of differences and/or deficiencies in the various ocean synthesis products is the input data stream. Different choices are made in data selection, and even different data sources are used. Systematic data errors have been identified and different approaches developed for reducing those biases, particularly in XBT temperatures, as mentioned above. For Argo, the issues concern float pressure sensors and salinity sensor drift (e.g., [19]). Systematic errors of even 1 dbar are a concern if trying to detect slow signals of global climate change. High quality CTD transects provide the standard for assessing data quality in profiling floats. Much work is yet to be done in assembling available shipboard datasets and analyzing them jointly with Argo to identify and correct systematic errors. Assembling the best-quality data is a multi-year endeavour [19].
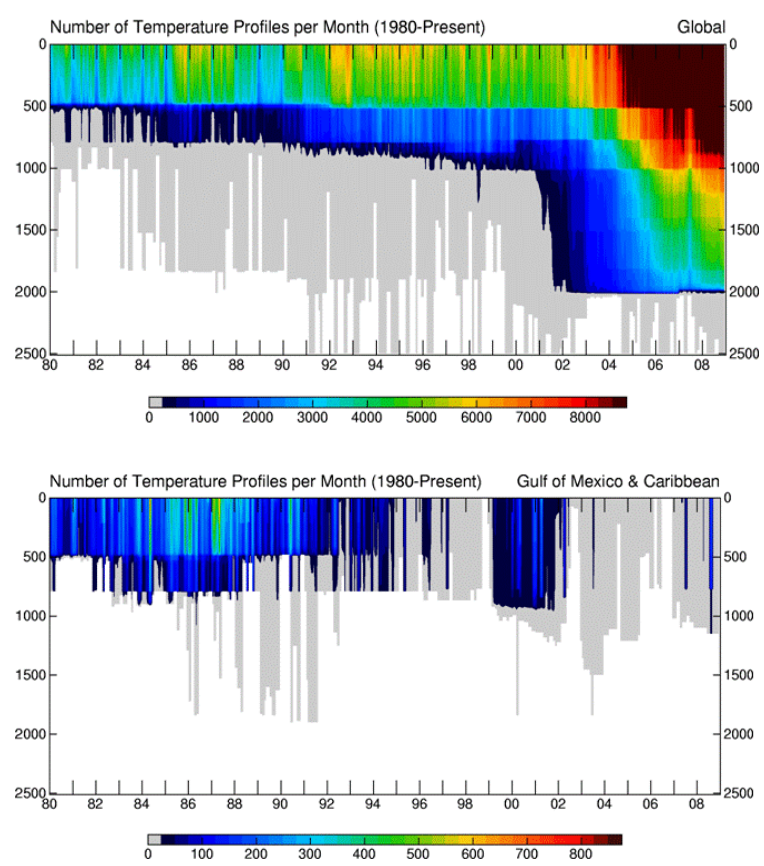

Figure 4. The number of global temperature observations per month as a function of depth. The data sources are XBTs, the global tropical mooring arrays and Argo floats. The upper panel is global; the lower panel is restricted to the Gulf of Mexico and the Caribbean.

The changing set of observation databases poses another challenge for the assimilation community. This is particularly so when different data sets are used in different systems. The time to re-synthesize data sets with the more sophisticated data assimilation methods precludes rapid refresh of synthesis products with potentially frequent updates in data corrections. This issue also highlights the importance of attention to the organization of data sets and the use of metadata and version control in the archive of all data. Reference [49] proposes that the community adopt standards for describing and versioning metadata, quality control (QC), and observational data.

Differences in QC procedures also introduce differences in assimilation products. A fundamental component of any analysis system, data QC must correctly identify observations that are obviously in error, as well as the more difficult process of identifying measurements that fall within acceptable ranges, but are nevertheless erroneous. Effective QC requires a set of preestablished, standardized test procedures, with results of the procedures clearly associated with the data values (e.g., [31] and [50]). At present, there are few agreedupon standards for ocean data QC and few cases where the procedures and results from different groups have 
been compared. The GODAE Quality Control Intercomparison Project [51] is taking the first step by comparing the outcomes of profile data QC procedures from five oceanographic centres. Results can be found at http://www.usgodae.org/ftp/outgoing/godae qc.

Even with the marked improvement in the global in situ data coverage with Argo, the current GOOS has a number of serious shortcomings. In addition to the decline in the marginal seas noted above, the deep ocean (below $2000 \mathrm{~m}$ ) and ice-covered regions remain largely unobserved. The need to observe the ocean over the full water column is evident from ocean analyses. Changes are not restricted to the upper ocean (Fig. 5 and also the discussion in [52] and [53]). Abyssal trends are apparent, especially in the Southern Ocean region, but these would be missed in most of the current in situ observations. Repeat observations from the World Ocean Circulation Experiment (WOCE) and CLIVAR indicate that some areas in the Southern Oceans have warmed significantly between 700 and $3000 \mathrm{~m}$ [52], as have many regions below $3000 \mathrm{~m}$ [53], so it is not clear that the current ocean state estimates are constrained well enough at depth. In general, the deep ocean can be expected to grow in importance with the time-scale of interest, so it is important for documentation and study of climate trends as well as for longer-term climate prediction that the observing system below $2000 \mathrm{~m}$ is improved.
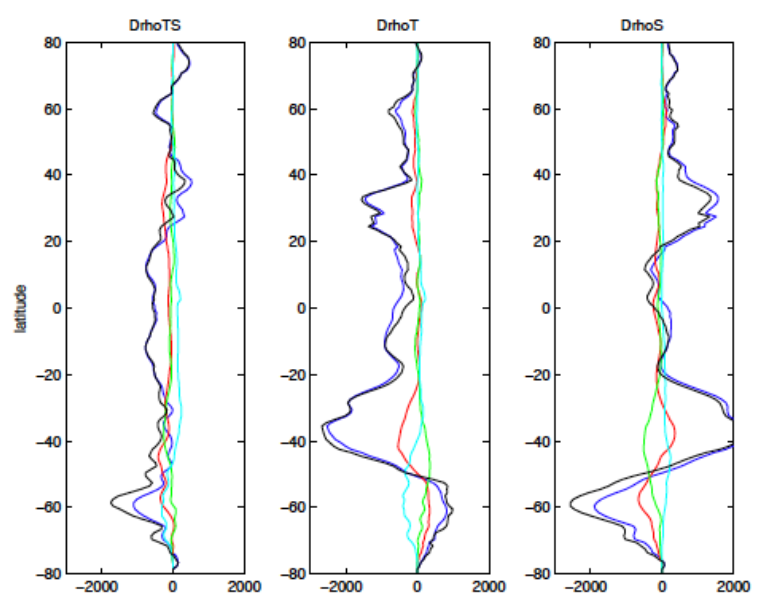

Figure 5. Vertical integrals of zonal average temperature and salinity trends, translated into density trends (abscissa, in $\mathrm{kg} / \mathrm{m}^{2} / \mathrm{yr}$ ) as a function of latitude (ordinate), from the ECCO-GODAE solution v3.73 [54]. Black: full water column; dark blue: 0-848 m; red: 848-1975 m; green: 1975-2450 $m$; cyan: 2450-5450 m. From [27].

Currently, full-depth ocean observations come from dedicated hydrographic cruises that can only sample a very small area of the deep ocean. In the future, these hydrographic cruises must be augmented by an array of deep floats, moored instruments, gliders, or a combination thereof (e.g., [53]). Improvements in remotely sensed measurements of vertically integrated ocean mass (or equivalently bottom pressure, see [22]) such as from the proposed GRACE-II mission could also help constrain the deep density field when combined with sea level and upper ocean information.

To improve estimates of climate variations, we also need to enhance information about boundary currents and transports through key regions, and pursue the satellite-derived sea-ice thickness from CryoSat-2 (CRYOgenic SATellite-2) and ICESat-2 (Ice, Cloud, and land Elevation Satellite-2) (e.g., [23]). For the Arctic, [23] makes the case for water temperature and salinity observations within the upper $800 \mathrm{~m}$ in the deep parts of the Arctic Ocean in addition to observations for monitoring riverine freshwater fluxes.

In addition to new observations, important satellite measurements such as altimetry, gravity (bottom pressure); SST from both microwave (all-weather) and infrared (high-resolution) sources, scatterometer winds, sea-ice concentrations and ocean colour must be maintained. Even with Argo, other elements of the in situ observing system need to be maintained and enhanced. In particular, the global tropical moored buoy array is essential for high frequency observations for short-term climate forecast initialization. The Tropical Atmosphere Ocean and Triangle Trans Ocean buoy Network (TAO/TRITON) arrays provide the backbone observing system for seasonal forecasts [8]. These need to be maintained because consistency of the observing system over time is an issue in the calculation of drifts and calibration of forecast skill. The planned tropical moored buoy array in the Indian Ocean, the Research Moored Array for African-Asian-Australian Monsoon Analysis and Prediction (RAMA), needs to be completed, not only for the Indian Ocean variability itself, but also to aid forecasts of intraseasonal variations that play a role in the evolution of El Niño events. Skillful seasonal forecasts remain a challenge in the tropical Atlantic so the enhancements to the Pilot Research Moored Array in the Atlantic (PIRATA) [55] should be maintained for sufficient duration for significant impacts on seasonal forecasts to be established. As with the TAO/TRITON array, any velocity data at the mooring arrays would be helpful for independent evaluation of the assimilation products. Of course, the ocean velocity field, at all depths, is poorly observed. Any velocity observations throughout the water column would be helpful not just for validation but also for input to high resolution, operational oceanography applications.

New satellite measurements like that of sea surface salinity will be available soon and need to be pursued in the future. The Soil Moisture and Ocean Salinity (SMOS, launched November 2009) and upcoming 
Aquarius (2011) missions will provide the first quasisynoptic view of ocean surface salinity, which should be beneficial to ocean synthesis. This will provide an additional constraint on the large-scale surface density field and also on the mixed layer salinity budget.

The extension of data assimilation systems inshore (see below) assumes that coastal observing systems will be developed to support them. Cost-effective in situ coastal observing systems will be a challenge. Many satellite observations also have issues near shore. The technical challenges for coastal altimetry are presented in [56], along with a description of efforts that are underway to improve products in the coastal zone and to develop calibration/validation systems for new data products. Water vapour and tidal corrections are particularly crucial, and their precision needs to be increased in the coastal zone. Further work is needed to improve satellite technology and capability in this environment. CryoSat2 (launched in April 2010), the Sentinel-3 satellites and the Surface Water Ocean Topography (SWOT) mission [57], with ability to resolve high-resolution features, hold a lot of promise for coastal oceanography and coastal ocean data assimilation [56].

\subsection{Surface Forcing}

Long atmospheric reanalyses have been a critical source of forcing for ocean model simulations and analyses. These reanalyses face similar issues to the ocean historical analyses - changing observing systems and lack of error estimates - that only compound the problem for climate analyses and predictions. The previous generation reanalyses (e.g., the National Centers for Environmental Prediction/National Center for Atmospheric Research (NCEP/NCAR) Reanalysis and ERA-40) had major global imbalances in heat and freshwater fluxes [43]. The latest generation, the Modern Era Retrospective-analysis for Research and Applications (MERRA) [58] and ERA-Interim [59] are improvements in this regard, but are relatively short for ocean climate analyses, covering only from 1979 and 1989, respectively, to the present. Although improved from previous reanalyses, they still show impacts of the changing observing system on global water and energy balances. For real-time oceanographic analyses, it is the real-time Numerical Weather Prediction (NWP), analyses and forecasts that provides the needed forcing.

The surface flux algorithms used in atmospheric reanalyses and NWP tend to be different from those derived from air-sea interaction experiments, leading to significant differences in derived flux estimates. Hence, the development of improved atmospheric datasets to force global ocean-ice climate models is a key area that needs continual attention. The ocean modelling community has tended to tackle this task itself. Three examples are: the forcing data set prepared for a global ocean-ice model comparison, the Coordinated Ocean- ice Reference Experiments (CORE) [60] using the atmospheric forcing dataset (based on the NCEP/NCAR Reanalysis) compiled by [61] and updated by [62]; an analogous dataset based on ECMWF reanalysis [63]; and the DRAKKAR Forcing Sets (DFS3 and DSF4 [64]) based on ERA-40 and tuned to fit the needs of the DRAKKAR model configurations [65]. The Objectively Analyzed air-sea Fluxes (OAFlux [66]) is another example of hybrid products that blend NWP, satellite and in situ variables. Reference [44] points out that these products also suffer from changes in the observing system and, possibly, changes in the operational NWP system. Hence, the problem of inhomogeneity remains in diagnostics of decadal variability and trends. Problems can also arise with a mismatch of scales when data from different sources are combined in flux algorithms.

Satellite observations are a key source of surface forcing data. Scatterometer missions are essential for estimates of surface momentum and turbulent heat fluxes. Improvements needed for the coming decade include improved sampling at high wind speeds and under rain conditions ([44], [67]) and resolution of the diurnal and inertial forcing. Remote sensing of latent and sensible heating remain a challenge [68] with considerable uncertainty in how to estimate near-surface air temperature and humidity remotely [69]. Measurements of surface shortwave radiation, and its penetration into the upper ocean, are essential to support simulations of interactions between ocean biology and physics. Satellite-derived rainfall estimates are essential for freshwater flux estimates. However, the uncertainty in precipitation over the ocean is still large - differences between satellite estimates and NWP products can be greater than $10 \mathrm{~mm}$ month $^{-1}$ in the tropics [70]. The planned Global Precipitation Measurement (GPM) mission should help reduce precipitation uncertainties in the future.

An additional challenge is the estimation of fluxes through sea ice, where the ocean surface climate is noticeably different from the open ocean. The difficult environmental conditions at high latitudes mean that flux observations there are extremely scarce. Existing gridded flux products can differ substantially, by 50 $\mathrm{Wm}^{-2}$ or more in the case of heat fluxes, and in many cases there is no clear consensus about which flux products are most reliable [71]. According to [71], desired improvements include: increases in the accuracy of scatterometer winds at high wind speed and of heat fluxes to achieve $0.01 \mathrm{Nm}^{-2}$ and $10 \mathrm{~W} \mathrm{~m}^{-2}$ accuracy (averaged over several days) with $25 \mathrm{~km}$ grid spacing. Achieving this will require a concerted plan to make better use of ships of opportunity to collect meteorological data, a targeted effort to deploy a few flux moorings in high wind regions, and improved satellite retrievals of flux related variables. 
In situ surface measurements are particularly important for calibration of satellite-derived fluxes and evaluation of NWP and reanalysis flux estimates. Reference [44] summarizes the various in situ sources of fluxes. They recommend expansion of the surface flux reference network under OceanSITES (OCEAN Sustained Interdisciplinary Time series Environment Observation System) [72], especially in higher latitudes and in areas with severe weather conditions, and expanding the shipbased measurement program. The increased coverage would help improve NWP products as well as the estimation of uncertainty in these products. The in situ measurements are also critical for climate quality calibration of satellite observations.

Constraints on surface fluxes may come increasingly from assimilating ocean data. However, the entanglement of model boundary layer error with forcing error is strong and care is needed in the interpretation of such inferred fluxes. Certainly, progress is needed in consistent estimation of air-sea fluxes using constraints from observations in the atmosphere and the ocean, perhaps in coupled models. However, the need for attention from NWP centres in continuously improving their surface analyses, especially through improved flux parameterizations, and updated reanalyses remains critical.

\subsection{Modelling and Assimilation Challenges}

Other challenges for ocean data assimilation lie in the covariance modelling of background (or forecast) and observation errors, including representation error, and in the ability of the observations to constrain the mesoscale ocean variability. Of course improving the models themselves is also a high priority.

The estimates of model and data errors dictate the outcome of the estimation product. Therefore, the ocean state estimation community needs to work closely with observationalists to obtain robust estimates of data errors (including biases), an important issue that is often left to assimilation groups. Of course, representation error is a function of the model, its resolution, and the phenomena of interest in the analysis. Little attention has been paid to the representation errors for in situ data to date; some progress is being made with satellite data, which is much more amenable to analysis because of its better sampling characteristics (e.g., [73], [74]). The new air-sea flux data set by [75] includes estimates of representativeness errors due to sampling and includes the representativeness errors for subdaily variability in its random error estimates.
Close collaborations between the assimilation, modelling, and observational communities are needed to understand model errors better, to assess where observations and models diverge, and develop methodologies to resolve differences. Reference [45] discusses origins of biases and differences between model simulations and between models and observations: shortcomings in grid resolution, both horizontal and vertical; poor numerical algorithms, subgridscale parameterizations, or representation of other climate components such as the atmosphere, cryosphere, ocean biogeochemistry, and land runoff; and possibly other reasons not yet identified.

Of central importance to ocean, state estimation is the ability to correct both temperature and salinity and maintain dynamical balances. This has been achieved through multivariate assimilation schemes using empirical orthogonal functions ([76], [77], [78] and [79]) or temperature-salinity covariances from asymptotic Kalman filter/smoothers (e.g., [80]) or ensemble-based filters (e.g., [81] and [82]) that are well suited to handle nonstationary stochastic processes in which the error structure of flows is highly anisotropic and time-varying. These multivariate relationships can also be important to effective assimilation of altimeter data (e.g., [83]). Reference [81] shows that with the multivariate covariances from an ensemble filter salinity errors at the equator are reduced by $45 \%$, vertical motion errors by $81 \%$, and the undercurrent errors by $50 \%$ compared with univariate assimilation of temperature only. Reference [46] discusses the importance of multivariate corrections to temperature, salinity and sea level and the positive impact on seasonal forecast skill. References [83] and [84] show that state-dependent multivariate covariances can be effectively estimated with coupled breeding approaches and that improvements in the salinity state estimates and density stratification have a positive impact on forecast skill. The 4DVar approaches implicitly include flowdependent relationships and balances but still require estimates of the background and model error statistics.

A sense of the critical nature of the treatment of salinity in the pre- Argo era, and the importance of Argo, can be gained from Fig. 6, where the ECMWF ocean data assimilation system (S3 [28]) has been used to assess the impact of Argo salinity observations on the salinity analysis in the upper $300 \mathrm{~m}$ (S300). There are many areas where the effect of temperature on S300 is contrary to the direct effect of using salinity [85]. S3 
uses the algorithm from [86] to correct salinity along isotherms to maintain important water mass properties, a technique that [87] shows improves upon conventional depth-level assimilation.
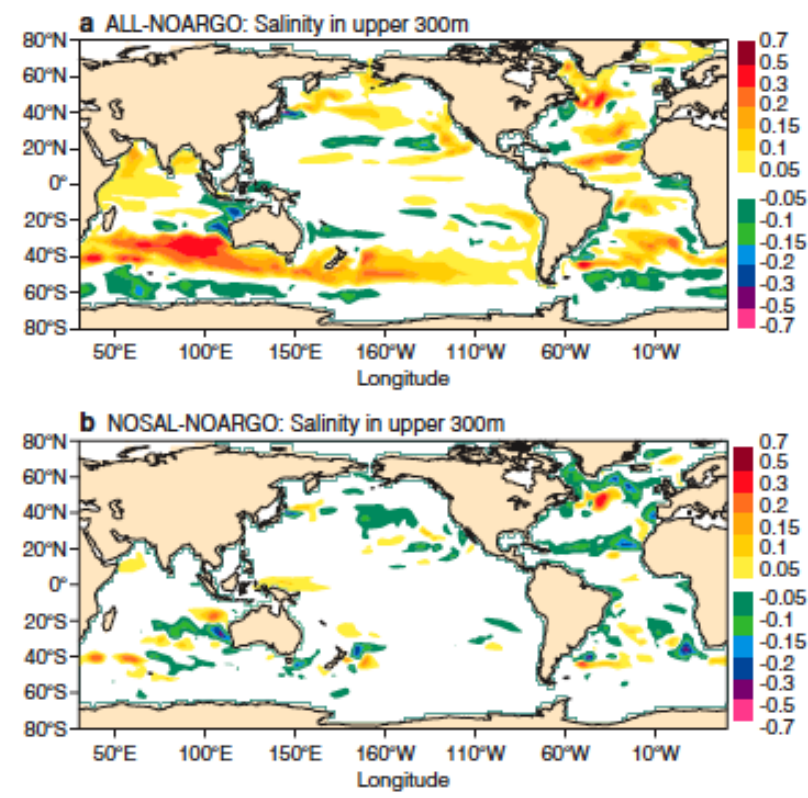

Figure 6. Impact of Argo on the average salinity in upper $300 \mathrm{~m}$ (psu) in the ECMWF S3 analysis: (a) Argo $T$ and $S$, and (b) Argo Tonly, after [85].

The quantification of model errors for the specification of forecast error covariances in 3DVar or Kalman filter/smoother approaches is only one area that needs attention. The identification of model error sources is also critical to 4Dvar estimation. Some model errors are attributable to multiple sources. For example, a biased SST estimate in the equatorial Pacific cold tongue could be related to errors in wind, surface heat flux, or mixing parameterizations and advection (also related to resolution). Determination of the appropriate "controls" and correct attribution of error sources are important to the fidelity of the estimation products.

The uncertainty in the analysis solution arising from assumptions made about the cost function - the imposition of balance and other constraints, error specifications, the controls - is as yet an unexplored area of investigation. A related question is the impact on the solution of requiring that the model equations be satisfied so that budgets can be balanced. For some climate applications, it has been argued that forcing the balance is necessary. Most ocean assimilation systems do not follow this approach. For atmospheric assimilation systems, the tendency has been to use the extent of imbalance as one measure of the quality of the system. Ocean assimilation systems would benefit from being evaluated in a similar vein. The impacts of some of these choices will only be understood through controlled intercomparisons where the same model, data, QC, and forcings are used.

Although many real-time operational oceanography assimilation efforts use resolutions of about $1 / 10^{\circ}$, most of the products for climate applications have resolutions that are too coarse to represent mesoscale eddies. Since eddies affect climate through their interaction with the larger scales, it is imperative that ocean state estimation for climate move towards eddy-permitting resolutions. An important issue is that the in situ data are not adequate to constrain the mesoscale and the emphasis is placed on multiple sources of altimeter data to capture eddy variability (e.g., [88]). The future SWOT mission [57] is expected to provide new insight to ocean variations at scales smaller than the $\sim 100 \mathrm{~km}$ scale currently possible.

Reference [1] outlines other issues related to resolution for operational oceanography as the user community is looking to extend models inshore, across the shelf, and into bays and estuaries. Attention is needed for better methods for nesting models, or for variable resolution and adaptive grids. Depending on the relevant dynamics of the situation (e.g., local topographic effects, wind wave, tidal currents, land freshwater input, etc.), assimilation methods have to be developed to constrain not only the large-scale (quasi-) geostrophic field but also fields influenced by small-scale nonlinear processes.

\section{THE FUTURE}

Ocean data assimilation has matured in significant ways over the last decade. With the advances made with satellite altimetry, Argo and the global tropical moored buoy arrays, and upcoming observations such as the completion of the RAMA array [18], satellite measurements of surface salinity [89], and highresolution ocean surface topography [57], we can be certain that further significant progress will emerge in the coming decade. Some exciting advances, like the contributions being made to observing system evaluation/design, the use of global ocean models at true eddy resolving resolution $\left(1 / 12^{\circ}\right.$ or better) [88], and the developments of assimilation with coupled oceanatmosphere models, are already underway.

\subsection{Integrated Earth System Analyses}

The various observations of Earth's environment are currently assimilated using techniques that typically consider the components of the Earth's climate system separately. As such, the state of one component is not usually constrained by the observations and dynamics of other components (except as external forcing) and the resulting state estimates are not necessarily consistent across the various components. This hampers research on the attribution of the variability and changes within the coupled system and limits the skill of climate 
prediction. For the ocean, the issue is not just coupling with the atmosphere, but also with sea-ice and ocean biogeochemistry, and also with the land surface.

There are many issues to be addressed in tackling this problem, not least of which are the differences in time scales for the ocean and atmosphere, both processes and observations, and the impact of physical imbalances on coupled physical-biogeochemical models. Another area of concern is the biases in coupled models (e.g., [45]) that will have a detrimental impact on state estimates during periods that are observation-challenged. Many aspects of ocean circulation simulation are improved with resolution in ocean-only models (e.g., [85]); however, resolution does not necessarily ameliorate important biases in coupled models. Nevertheless, it is the role of data assimilation to compensate for errors, including biases with the appropriate formulation.

There are a few groups pioneering the new horizon of
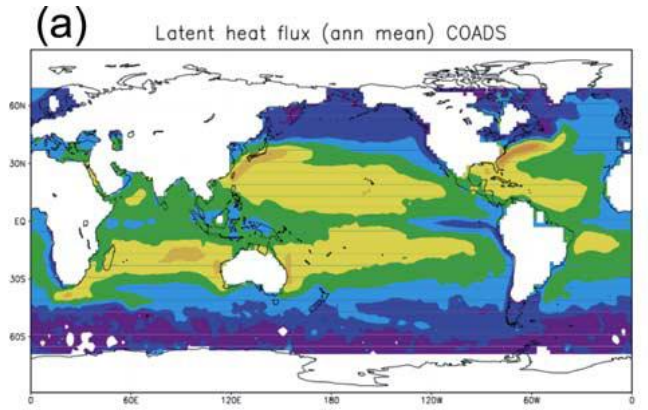

(c)

Latent heat flux (ann mean) NCEP2

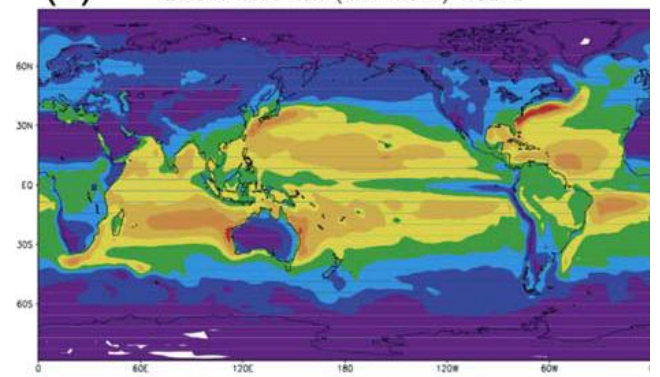

estimation using coupled ocean-atmosphere models. Reference [81] uses an ensemble Kalman filter implementation and assimilates a pre-existing atmospheric analysis along with the ocean observations. Using 4DVar, [90] estimates drag (coupling) coefficients, used in the calculation of momentum and heat fluxes between the ocean and atmosphere, along with the ocean and atmospheric states. In addition to improved representation of fluxes (e.g., Fig. 7) and climate variations, the coupled assimilation improves the forecast of the 1997-98 El Niño. Reference [91] assimilates ocean observations into a coupled model and finds an improvement in several atmospheric fields over those from an atmosphere-only run using observed SSTs. Coupled estimation efforts are expected to evolve markedly as the climate community continues to improve initialization for seasonal climate prediction and embarks on decadal prediction.

(b) Latent heat flux (ann mean) assimilation
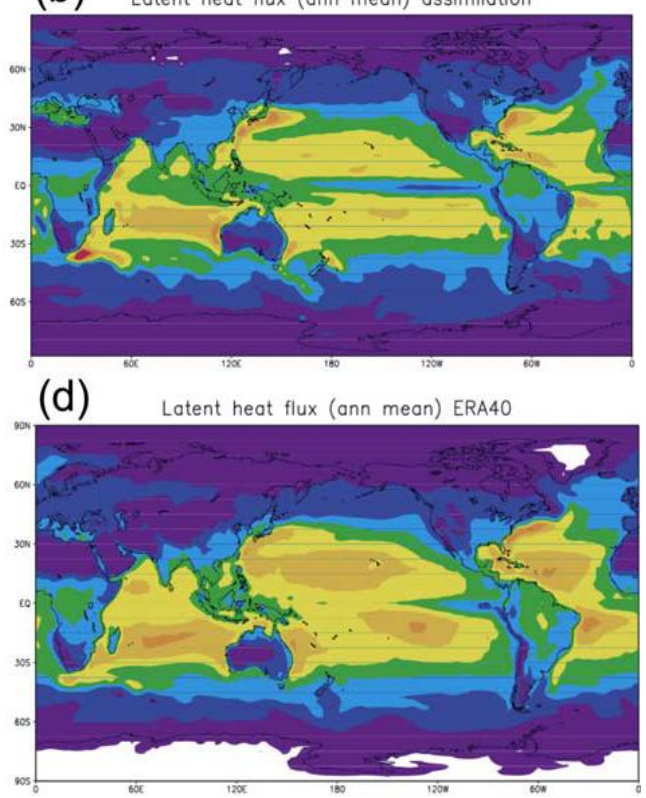

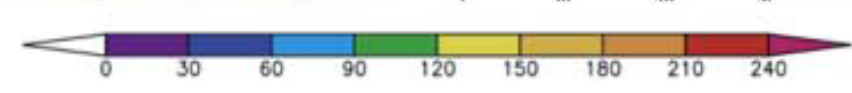

Figure 7. Annual averages of surface latent heat flux ( $W \mathrm{~m}^{-2}$, positive upward) taken from (a) the Comprehensive Ocean-Atmosphere Data Set, (b) coupled 4D-Var, (c) NCEP2 reanalysis, and (d) ERA-40 reanalysis. From [90].

Data assimilation is also important for estimating seaice concentrations, which, like SST, are needed as lower boundary conditions for the atmosphere as well as for ocean state estimation [92]. Simple analysis techniques have been used in weather prediction centres for some time. Now, more advanced techniques (including an ensemble Kalman filter [93] and a variational implementation [94]) are starting to emerge as ocean models and assimilation systems evolve to be truly global. As an example, [92] presents results from the hybrid experiment of [94] where an ensemble Kalman filter is used to estimate parameters for the background error covariances used in the 3DVar.

Future developments in sea-ice assimilation will be in two main areas. The first is the development of techniques to incorporate as many operational observations as feasible. Currently, the observations that have been assimilated are those from passive microwave instruments, ice charts and ice drift. Other observations, such as active radar and satellite-derived sea-ice thickness from CryoSat-2 and the future ICESat2 , will be incorporated over the coming years. The 
second development area lies in improving the prior estimate provided by coupled atmosphere-ice-ocean models that propagate information from past observations.

With the growth of operational oceanography, the demand has also been growing for data and information relevant to understanding the global marine ecosystem, unravelling the functions of the marine ecosystem in a changing climate, and contributing to sustainable management of marine resources. Reference [95] provides a GODAE view of recent progress in integrating biogeochemistry and ecology into ocean data assimilation. They note the importance of resolution and the need to consider additional processes, such as river runoff, as the focus moves to the continental margin. Coupling biological models to physical hindcasts from assimilative models has sometimes led to degraded simulations of biogeochemical variables (e.g., [96], [97]). However, [97] showed that their combined assimilation of physical and nutrient data into a coupled physical-biogeochemical model has a positive impact on modeled phytoplankton patterns in the North Atlantic.

Examples of remotely sensed ocean colour assimilation include [98] and [99], in which global syntheses of satellite-derived chlorophyll- $a$ have been undertaken with the NASA Ocean Biogeochemical Model (Fig. 8). Comparison with independent in situ data for the period 1998-2004 shows a significant improvement of the chlorophyll estimate. In [98], the global RMS log error of chlorophyll estimated by the model is reduced by the assimilation from $53 \%$ to $13 \%$ above the error of SeaWiFS. Regionally, the assimilation estimate exhibits smaller errors than SeaWiFS data in several ocean basins. (a)

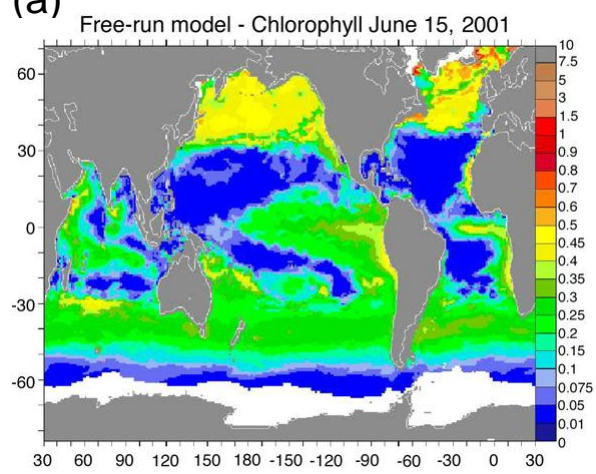

(b)

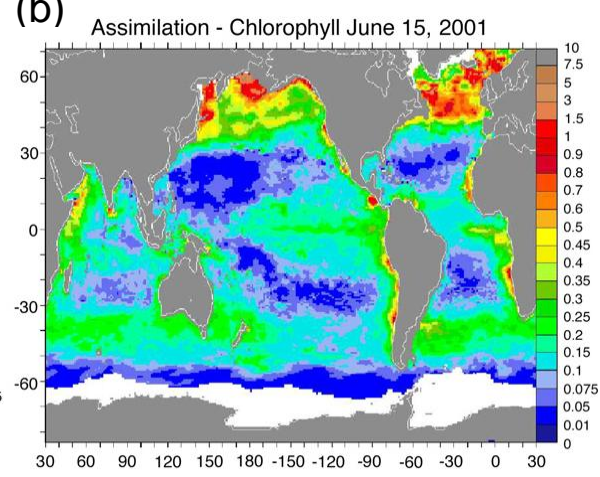

(c)

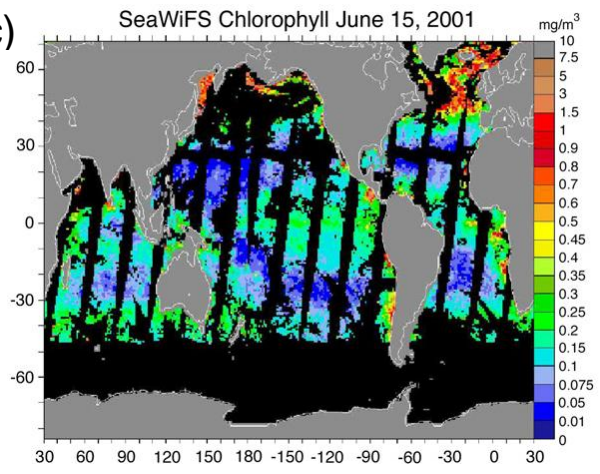

Figure 8. Total surface chlorophyll $\left(\mathrm{mg} / \mathrm{m}^{3}\right)$ for June 15, 2001 from (a) a model simulation, (b) an assimilation of SeaWiFS data, and (c) SeaWiFS. White indicates sea ice. The assimilation significantly improves the chlorophyll estimate of the free-running model simulation. From [98].

During the next decade, coupled physicalbiogeochemical assimilation can be expected to mature, providing new insights not only to ocean biological variations and the marine carbon cycle but also into the feedbacks within the physical climate system. To make further progress, issues to be addressed include the need to improve ocean model representation of some physical variables such as upper-ocean vertical fluxes that are critically important to biological activity. The lack of relevant observations is probably the most severe limitation to expansion of operational systems to biogeochemical and ecosystem applications. Thus, ocean observing systems will need to be expanded with, for example, intensified deployments of in situ sensors for $\mathrm{O}_{2}$ and chlorophyll, and inclusion of new sensors for nutrients, zooplankton, etc., and new satellite missions for ocean color, lidar systems for mixed-layer depths, and wide-swath altimeters for coastal sea levels. Improved methods will need to be developed to assimilate these new measurements.

The pathway to a fully integrated Earth system analysis 
will continue to proceed incrementally, with advances in coupling of two or three components at a time.

\subsection{Realizing the potential of analyses and models in observing system design}

An important and emerging role for ocean data assimilation is the assessment of the contribution of the various components of the observing system and scientific guidance for improved design and implementation of the ocean observing system. As ocean models and assimilation systems have improved in quality over the years, ocean analysis and forecasting systems and associated tools, such as adjoint sensitivity diagnostics, have become powerful means to assess the impact of the observing system for particular applications, to identify gaps and ultimately improve the efficiency/effectiveness of the observing system.

Observing System Experiments (OSEs) where different components of the GOOS are systematically withheld can help quantify the impact of each observation type on the quality of analyses or the skill of a forecast. Various other techniques, including observing system simulation experiments (OSSEs), adjoint- and ensemble-based approaches, can be used to aid the design and evaluation of ocean observing systems. Examples of various evaluations of the observing system can be found in [27], [46] and [100].

One recurring result from different OSEs includes the complementary nature of different observation types (e.g., [26], [28] and [101]). For example, [26] performed a series of OSEs to compare the relative impact of Argo, SST and sea level anomaly (SLA) observations on an eddy-resolving ocean reanalysis. They systematically withheld altimeter, Argo and SST observations. They found that satellite SST observations are the only observation type considered that have the potential to constrain the circulation in shallow seas and over wide continental shelves; altimetry is the only observation type that even goes close to constraining the mesoscale ocean circulation; and Argo observations are the only observation type that constrains sub-surface temperature and salinity (Fig. 9). None of the observation types in the GOOS was found to be redundant. Each different observation type brings unique contributions to the GOOS and all observation types should be routinely assimilated by forecast and reanalysis products and, most importantly, maintained by the international community. The consistent use of and impact from SST observations is a credit to the GODAE High Resolution SST (GHRSST) program that provides high-level quality controlled SST data in near real-time [21].

Another result that is common to many studies is the necessity of assimilation of altimeter data to represent mesoscale variability (e.g., [26], [33] and [102]). Reference [103] has shown that four altimeters are needed in real time to get similar quality performance as two altimeters in delayed time.

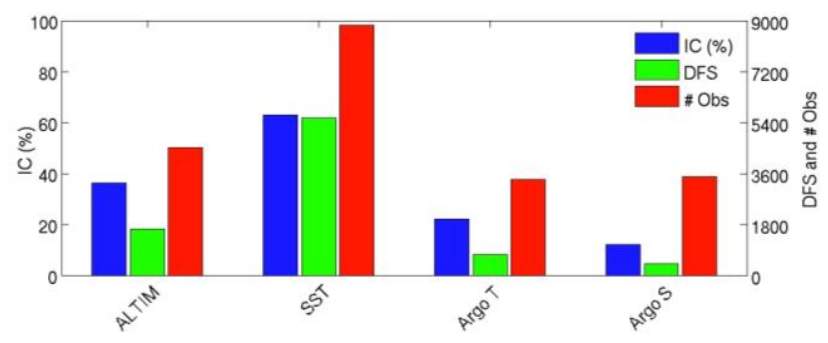

Figure 9. Preliminary estimates of the Information Content (IC; \%), degrees of freedom of signal (DFS) and the number of assimilated super-observations (\# Obs) for the BLUElink (Ocean forecasting Australia) reanalysis system in the region $90-180^{\circ} \mathrm{E}$, $60^{\circ}$ S-equator, computed for 1 January 2006. The scale for the IC is to the left and the scale for the DFS and \# Obs is to the right, from [100].

A series of OSEs using the $1 / 9^{\circ}$ UK Met Office system quantify the analysis improvements according to the number of altimeters used in the assimilation (Fig. 10). The impact of different numbers of altimeters was assessed by comparing the analyzed SLA with the assimilated along-track altimeter data, and the analyzed surface velocities with those derived from surface drifting buoys (which were not assimilated). The addition of the first altimeter has the greatest impact. The results are different for different regions. Mesoscale dynamics in the Northeast Atlantic seem to be constrained better by the altimeters than in the Northwest Atlantic.

The potential impact of remotely sensed sea surface salinity (SSS) from SMOS or Aquarius on the forecast skill of the Mercator Ocean system has been assessed by [104] through a series of OSSEs. They concluded that the level of observation error is critical to the impact of this new observation type, consistent with the result of [105], which assessed the theoretical impact of SSS observations.

Other than for seasonal forecast skill, little has been done to assess the value of ocean observing capabilities with respect to large-scale ocean circulation diagnostics and their fluctuations on climate timescales (i.e. decadal and beyond). Some preliminary analysis of OSEs can be found in [27], [106], [107] and [108]. Many outstanding questions, such as the optimal ocean observing system for estimating long-term freshwater and heat transports within the global climate system, remain.

Even in the atmospheric community where OSSEs have a longer history, the usefulness of OSSEs is not universally accepted. Certainly, care is needed in the interpretation; and the careful simulation of the 
observations with realistic error characteristics from a simulation that has been validated to some extent in terms of its representation of nature is essential. Comparison of results from several systems to assess the robustness of the results is also important. This is also important for OSEs.

\subsection{Monitoring the Ocean and the Observing System}

Ocean data assimilation provides a comprehensive and powerful approach to monitoring the global ocean and, as such, is an important adjunct to the observing system. For the future, we envision a regular evaluation of the state of the ocean over the full water column, providing information about important ocean indices to both science and application communities on a regular basis.

In addition, it is expected that the assimilation systems and associated tools will provide routine mechanisms for evaluation of the observing system. As a guide to tools that may be developed, the ocean community can look to the emerging tools in the atmospheric assimilation community. These tools represent diagnostics from analysis and forecasts systems that are relatively inexpensive to compute. For example, analysis sensitivity experiments and adjoint tools can quantify the impact of each individual observation on an analysis and forecast (e.g., [109]), albeit through a single pre-determined metric. The identification of persistent problems (e.g., negative impacts) with particular observations may indicate sensor drifts, particularly if consistent across several assimilation and forecast systems. Reference [110] shows how the adjoint tools in conjunction with OSEs can provide insight into the synergy between different observation types. These tools are now being implemented into the U.S. Navy's ocean analysis and forecast systems.
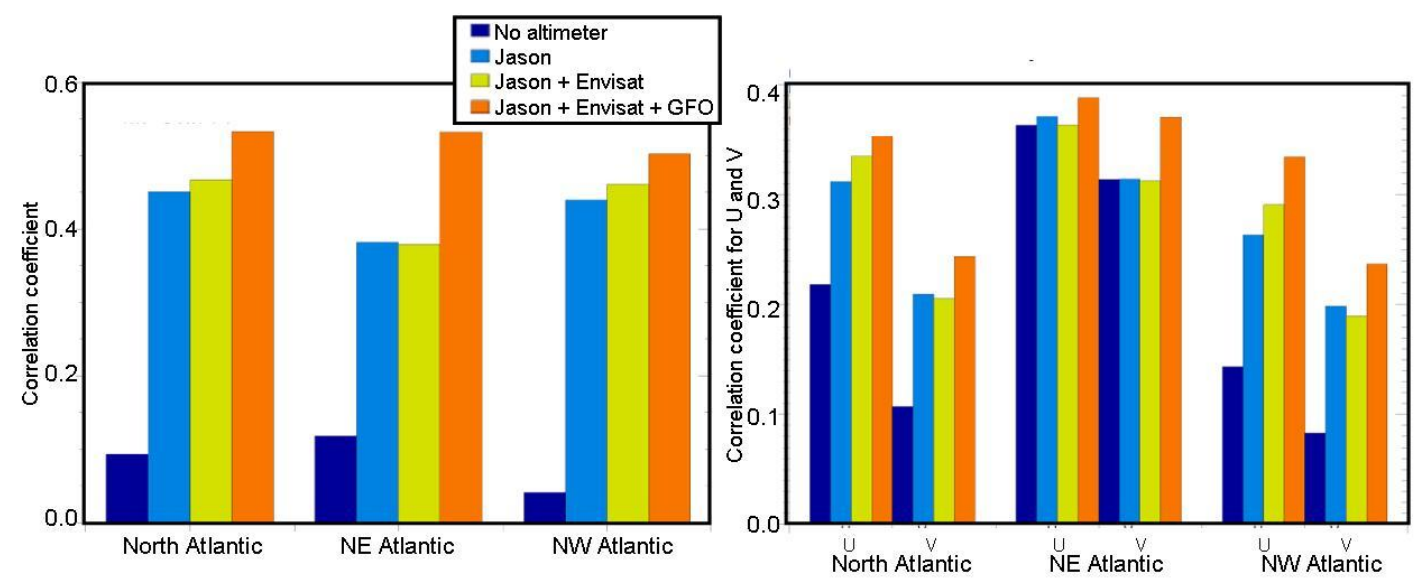

Figure 10. Anomaly correlation between forecast SLA and along-track altimetric SLA from all satellites (left) and forecast near-surface velocity and near-surface velocity derived from drifting buoys (right). The results are based on a series of OSEs that assimilate SLA data from 0-3 satellites, using the $1 / 9^{\circ}$ North Atlantic FOAM configuration for the first 3 months of 2006.

Ocean syntheses should also be used in improving data quality by, for example, providing the "background" used in statistical checks. This feedback loop could be important in ensuring that ocean syntheses provide the best possible analyses of current and past climate. It might also help refine bias corrections of observations such as those needed for historical XBTs.

Because the GOOS is constantly changing, results from OSEs quickly become obsolescent and a new paradigm is needed to monitor and evaluate the GOOS [100]. The
GODAE OceanView community is shifting their efforts to transition their OSE/OSSE activities towards routine monitoring of the GOOS. Some initial steps have been taken to coordinate these activities. Specifically, agreement is sought on: how GODAE partners can and should move towards routine monitoring of the GOOS; how this can be coordinated between the international groups; and a staged plan for moving these activities towards routine monitoring, so that the GODAE OceanView community can influence the ongoing design and assessment of the GOOS. 


\section{RECOMMENDATIONS}

Several recommendations are made here to improve the GOOS, the collaborations between the assimilation and observation communities, and the assimilation systems themselves. With these improvements, we can realize the potential of assimilation systems to synthesize observations to provide information that is more extensive than the information that can be gleaned from individual observations - for an impact on operational oceanography and climate analysis and forecasts.

\subsection{Recommendations on observations}

- Systematic, sustained observations of the ocean and its forcing are critical to the improvement of decadal and longer-term ocean state estimation. At minimum, the existing GOOS must be maintained. For the global observing system in support of real-time and climate analyses, the requirement is for the maintenance of Argo as well as important satellite measurements such as altimetry, gravity (bottom pressure), microwave and infrared-based SST, scatterometer winds, precipitation, ocean colour, and microwave-based sea-ice concentration. In addition, the global tropical moored buoy arrays (including RAMA and PIRATA) are essential for their provision of high frequency observations for short-term climate forecast initialization.

- To improve future ocean climate estimates, the in situ observing system should be extended to include full-depth Argo -type measurements. Measurements in marginal seas and ice-covered regions are important for both real-time and climate analyses.

- In addition to the sustained observations, the development of new observing systems such as measurements of sea-ice thickness from space and wide swath altimetry (SWOT) are encouraged.

- Improvements in altimetry for coastal regions, from existing measurements and especially from future highresolution altimetry, should be pursued.

- Observations are needed for assimilation into ocean biogeochemistry and ecosystem models: deployments of in situ sensors for $\mathrm{O}_{2}$ and chlorophyll, and inclusion of new sensors for nutrients, zooplankton, etc., and hyperspectral satellite measurements of ocean colour.

\subsection{Recommendations on surface forcing}

- The surface flux reference network under OceanSITES, especially in higher latitudes and in areas with severe weather conditions, should be expanded along with the ship-based measurement program. The increased coverage would help improve NWP products as well as the estimation of uncertainty in these products. Increased coverage will also improve satellite calibration.
- Satellite measurements of air-sea fluxes should continue to be a priority, particularly scatterometer winds and global precipitation.

- Atmospheric reanalysis projects should continue to be updated and attention should be placed on improving surface flux estimates in NWP and reanalysis products.

- Land freshwater input to the ocean (ice melting, river runoff, ground water seepage) needs to be better determined.

\subsection{Recommendations on the input data streams}

- Standard QC procedures should be developed.

- Appropriate metadata needs to be included with each observation so that its heritage and the history of corrections are available to assimilation groups.

\subsection{Recommendations on modelling and data assimilation}

- Much needs to be done over the next decade to characterize the uncertainties in each synthesis product.

- To fully understand the differences between the analysis products and to make further improvements in assimilation capabilities, a concerted comparison effort is needed wherein runs are undertaken with the same data and forcing and the analysis diagnostics are expanded to look at innovations, residuals and the details of data impacts.

- Progress needs to be made in dynamically consistent coupled atmosphere/ocean/sea-ice estimation to provide both a consistent view of Earth's climate variability and to improve the initialization for coupled climate predictions.

- Ocean state estimates should be maintained and viewed as an integral part of the ocean observing and information system.

\section{REFERENCES}

1. Bell, M., Le Traon, P.Y., Smith, N., Lefebvre, M. \& Wilmer-Becker, K. (2009). Overview of GODAE. Oceanography, 22(3), 14-21.

2. Le Traon, P.Y., Bell, M., Dombrowsky, E., Schiller, A. \& Wilmer Becker, K. (2010). GODAE

OceanView: from an Experiment Towards a LongTerm Ocean Analysis and Forecasting International Program. In these proceedings (Vol. 2), doi:10.5270/OceanObs09.cwp.57.

3. Davidson, F.J.M., \& Co-Authors (2009). Applications of GODAE Ocean Current Forecasts to Search and Rescue and Ship Routing. Oceanography, 22(3), 176-181. 
4. Hackett, B., Comerma, E., Daniel, P. \& Ichikawa, H. (2009). Marine Oil Pollution Prediction. Oceanography, 22(3), 168-175.

5. Ji, M., Leetmaa, A. \& Derber, J. (1995). An Ocean Analysis for Seasonal to Interannual Climate Studies. Mon. Wea. Rev. 123, 460-481.

6. Behringer, D.W., Ji, M. \& Leetmaa, A. (1998). An Improved Coupled Model for ENSO Prediction and Implications for Ocean Initialization. Part I: The Ocean Data Assimilation System. Mon. Wea. Rev. 126, 1013-1021.

7. Segschneider, J., Anderson, D.L.T. \& Stockdale, T.N. (2000). Towards the Use of Altimetry for Operational Seasonal Forecasting. J. Clim. 13, 3116-3138.

8. Balmaseda, M.A \& Co-Authors (2010). Initialization for Seasonal and Decadal Forecasts. In these proceedings (Vol. 2), doi:10.5270/OceanObs09.cwp.02.

9. Xue, Y. \& Co-Authors (2010). Ocean State Estimation for Global Ocean Monitoring: ENSO and Beyond ENSO. In these proceedings (Vol. 2), doi:10.5270/OceanObs09.cwp.95.

10. Stammer D. \& Co-Authors (2002). The Global Ocean Circulation During 1992-1997 Estimated from Ocean Observations and a General Circulation Model. J. Geophys. Res. 107, 3118, doi:10.1029/2001JC000888.

11. Carton, J.A. \& Giese, B.S. (2008). A Reanalysis of Ocean Climate using Simple Ocean Data Assimilation (SODA). Mon. Wea. Rev. 136, 29993017.

12. Lee, T. \& Co-Authors (2010). Ocean State Estimation for Climate Research. In these proceedings (Vol. 2), doi:10.5270/OceanObs09.cwp.55.

13. Cummings, J. \& Co-Authors (2009). Ocean Data Assimilation Systems for GODAE. Oceanography 22(3), 96-109.

14. Dombrowsky, E. \& Co-Authors (2009). GODAE Systems in Operations. Oceanography 22(3), 8095.

15. Wilson, S. \& Co-Authors (2010). Ocean Surface Topography Constellation: The Next 15 Years in Satellite Altimetry. In these proceedings (Vol. 2), doi:10.5270/OceanObs09.cwp.92.

16. Goni, G. \& Co-Authors (2010). The Ship of Opportunity Program. In these proceedings (Vol. 2), doi:10.5270/OceanObs09.cwp.35.

17. Hood, M. \& Co-Authors (2010). Ship-Based Repeat Hydrography: A Strategy for a Sustained Global
Program. In these proceedings (Vol. 2), doi:10.5270/OceanObs09.cwp.44.

18. McPhaden, M.J. \& Co-Authors (2010). The Global Tropical Moored Buoy Array. In these proceedings (Vol. 2), doi:10.5270/OceanObs09.cwp.61.

19. Freeland, H. \& Co-Authors (2010). Argo - A Decade of Progress. In these proceedings (Vol. 2), doi:10.5270/OceanObs09.cwp.32

20. Reynolds, R. W., Rayner, N.A., Smith, T.M., Stokes, D.C. \& Wang, W. (2002). An Improved In Situ and Satellite Analysis for Climate. J. Clim. 15, 1609-1625.

21. Donlon, C.J. \& Co-Authors (2010). Successes and Challenges for the Modern Sea Surface Temperature Observing System. In these proceedings (Vol. 2), doi:10.5270/OceanObs09.cwp.24.

22. Jayne, S.R., Wahr, J.M. \& Bryan, F.O. (2003). Observing Ocean Heat Content Using Satellite Gravity and Altimetry. J. Geophys. Res. 108, 3031, doi:10.1029/2002JC001619.

23. Kwok, R. \& Co-Authors (2010). Combining Satellite Altimetry, Time-Variable Gravity, and Bottom Pressure Observations to Understand the Arctic Ocean. In these proceedings (Vol. 2), doi:10.5270/OceanObs09.cwp.50.

24. Hernandez, F. \& Co-Authors (2009). Validation and Intercomparison Studies within GODAE. Oceanography 22(3), 128-143.

25. Stammer, D. \& Co-Authors (2010). Ocean Information Provided Through Ensemble Ocean Syntheses. In these proceedings (Vol. 2), doi:10.5270/OceanObs09.cwp.85.

26. Oke, P. R. \& Schiller, A. (2007). Impact of Argo, SST and Altimeter Data on an Eddy-resolving Ocean Reanalysis. Geophys. Res. Lett. 34, L19601, doi:10.1029/2007GL031549.

27. Heimbach, P. \& Co-Authors (2010). Observational Requirements for Global-Scale Ocean Climate Analysis: Lessons from Ocean State Estimation. In these proceedings (Vol. 2), doi:10.5270/OceanObs09.cwp.42.

28. Balmaseda, M.A., Vidard A. \& Anderson, D.L.T. (2008). The ECMWF ORA-S3 Ocean Analysis System. Mon. Wea. Rev. 136, 3018-3034.

29. Behringer, D.W. (2007). The Global Ocean Data Assimilation System at NCEP. 11th Symposium on Integrated Observing and Assimilation Systems for Atmosphere, Oceans, and Land Surface, AMS 87th Annual Meeting, San Antonio, Texas, 12pp. 
30. Domingues, C.M. \& Co-Authors (2008). Improved Estimates of Upper-ocean Warming and Multidecadal Sea-level Rise. Nature 453, 1090-1093, doi:10.1038/nature07080.

31. Ingleby B. \& Huddleston, M. (2007). Quality Control of Ocean Temperature and Salinity Profiles - Historical and Real-time Data. J. Mar. Syst. 65 , $158-175$.

32. Köhl, A. \& Stammer, D. (2008). Decadal Sea Level Changes in the 50-year GECCO Ocean Synthesis. J. Clim. 21, 1866-1890.

33. Martin, M.J., Hines, A. \& Bell, M.J. (2007). Data Assimilation in the FOAM Operational ShortRange Ocean Forecasting System: A Description of the Scheme and Its Impact. Q. J. Roy. Meteorol. Soc. 133, 981-995.

34. Masina S., Di Pietro, P. \& Navarra, A. (2004). Interannual-to-Decadal Variability of the North Atlantic From an Ocean Data Assimilation System. Clim. Dyn. 23, 531-546.

35. Smith, D. M. \& Murphy, J.M. (2007). An Objective Ocean Temperature and Salinity Analysis Using Covariances from a Global Climate Model. J. Geophys. Res. 112, C02022, doi:10.1029/2005JC003172.

36. Sun, C. \& Co-Authors (2007). Comparison and Sensitivity of ODASI Ocean Analyses in the Tropical Pacific. Mon. Wea. Rev. 135, 2242-2264.

37. Weaver, A. T., Vialard, J. \& Anderson, D.L.T. (2003). Three- and Four-dimensional Variational Assimilation with a General Circulation Model of the Tropical Pacific Ocean. Part I: Formulation, Internal Diagnostics, and Consistency Checks. Mon. Wea. Rev. 131, 1360-1378.

38. Gouretski, V. \& Koltermann, K.P. (2007). How Much is the Ocean Really Warming? Geophys. Res. Lett. 34, L01610, doi:10.1029/2006GL027834.

39. Wijffels, S. \& Co-Authors (2008). Changing Expendable Bathythermograph Fall Rates and Their Impact on Estimates of Thermosteric Sea Level Rise, J. Clim. 21, 5657-5672.

40. Ishii, M. \& Kimoto, M. (2009). Reevaluation of historical ocean heat content variations with timevarying XBT and MBT depth bias corrections. $J$. Oceanogr. 65, 287-299.

41. Levitus, S., Antonov, J.I., Boyer, T.P., Locarnini, R.A., Garcia, H.E. \& Mishonov, A.V. (2009). Global Ocean Heat Content 1955-2008 in Light of Recently Revealed Instrumentation Problems. Geophys. Res. Lett. 36, L07608, doi:10.1029/2008GL037155.
42. Lombard, A., Garric, G. \& Penduff, T. (2009). Regional Patterns of Observed Sea Level Change: Insights from a $1 / 4^{\circ}$ Global Ocean/Sea-ice Hindcast. Ocean Dyn. 59, 433-449.

43. Trenberth, K. \& Co-Authors (2010). Atmospheric Reanalyses: A Major Resource for Ocean Product Development and Modeling. In these proceedings (Vol. 2), doi:10.5270/OceanObs09.cwp.90.

44. Fairall, C. \& Co-Authors (2010). Observations to Quantify Air-Sea Fluxes and their Role in Climate Variability and Predictability. In these proceedings (Vol. 2), doi:10.5270/OceanObs09.cwp.27.

45. Griffies, S. \& Co-Authors (2010). Problems and Prospects in Large-Scale Ocean Circulation Models. In these proceedings (Vol. 2), doi:10.5270/OceanObs09.cwp.38.

46. Balmaseda, M.A \& Co-Authors (2010). Role of the Ocean Observing System in an End-to-End Seasonal Forecasting System. In these proceedings (Vol. 1), doi:10.5270/OceanObs09.pp.03.

47. Carson, M. \& Harrison, D.E. (2008). Is the Upper Ocean Warming? Comparisons of 50-year Trends from Different Analyses. J. Clim. 21, 2259-2268.

48. Testor, P. \& Co-Authors (2010). Gliders as a Component of Future Observing Systems. In these proceedings (Vol. 2), doi:10.5270/OceanObs09.cwp.89.

49. Snowden, D. \& Co-Authors (2010). Metadata Management in Global Distributed Ocean Observation Networks. In these proceedings (Vol. 2), doi:10.5270/OceanObs09.cwp.84.

50. Gronell, A. \& Wijffels, S.E. (2008). A Semiautomated Approach for Quality Controlling Large Historical Ocean Temperature Archives. J. Atmos. Oceanic Tech. 25, 990-1003.

51. Cummings, J., Brassington, G., Keeley, R., Martin, M. \& Carval, T. (2010). GODAE Ocean Data Quality Control Intercomparison Project. In these proceedings (Annex).

52. Palmer, M. \& Co-Authors (2010). Future Observations for Monitoring Global Ocean Heat Content. In these proceedings (Vol. 2), doi:10.5270/OceanObs09.cwp.68.

53. Garzoli, S. \& Co-Authors (2010). Progressing Towards Global Sustained Deep Ocean Observations. In these proceedings (Vol. 2), doi:10.5270/OceanObs09.cwp.34.

54. Wunsch, C. \& Heimbach, P. (2007). Practical Global Oceanic State Estimation. Physica D 230, 197-208. 
55. Bourlès, B. \& Co-Authors (2008). The PIRATA Program: History, Accomplishments, and Future Directions. Bull. Amer. Meteor. Soc. 89, 11111125.

56. Cipollini, P. \& Co-Authors (2010). The Role of Altimetry in Coastal Observing Systems. In these proceedings (Vol. 2), doi:10.5270/OceanObs09.cwp.16.

57. Fu, L. \& Co-Authors (2010). The SWOT (Surface Water and Ocean Topography) Mission. In these proceedings (Vol. 2), doi:10.5270/OceanObs09.cwp.33.

58. Bosilovich, M.J. \& Co-Authors (2006). NASA's Modern Era Retrospective-analysis for Research and Applications (MERRA). U.S. CLIVAR Variations 4(2), 5-8.

59. Dee, D. \& Uppala, S. (2008). Variational Bias Correction in ERA-Interim. ECMWF Tech. Mem. No. 575, 26 pp.

60. Griffies, S.M. \& Co-Authors (2009). Coordinated Ocean-ice Reference Experiments (COREs), Ocean Model. 26, 1-46.

61. Large, W. \& Yeager, S. (2004). Diurnal to Decadal Global Forcing for Ocean and Sea-ice Models: The Data Sets and Flux Climatologies. NCAR Technical Note: NCAR/TN-460+STR, 109 pp.

62. Large, W. \& Yeager, S. (2009). The Global Climatology of an Interannually Varying Air-sea Flux Data Set. Clim. Dyn. 33, 341-364, doi:10.1007/s00382-008-0441-3.

63. Röske, F. (2006). A Global Heat and Freshwater Forcing Dataset for Ocean Models. Ocean Model. 11, 235-297.

64. Brodeau, L., Barnier, B., Treguier, A.-M.,Penduff, T. \& Gulev, S. (2010). An ERA40 Based Atmospheric Forcing for Global Ocean Circulation Models. Ocean Model. 31, 88-104.

65. Drakkar Group (2007). Eddy-permitting Ocean Circulation Hindcasts of Past Decades. CLIVAR Exchanges, No 42, 12(3), 8-10.

66. Yu, L. \& Weller, R.A. (2007). Objectively Analyzed Air-sea Heat Fluxes for the Global Ice-free Oceans (1981-2005). Bull. Amer. Meteor. Soc. 88, 527539.

67. Bourassa, M. \& Co-Authors (2010). Remotely Sensed Winds and Wind Stresses for Marine Forecasting and Ocean Modeling. In these proceedings (Vol. 2), doi:10.5270/OceanObs09.cwp.08.

68. Liu, J. \& Curry, J. (2006). Variability of the Tropical and Subtropical Ocean Surface Heat Flux
During 1989-2000. Geophys. Res. Lett. 33, L05

706, doi:10.1029/2005GL0024 809.

69. Jackson, D. L., Wick, G.A. \& Bates, J.J. (2006). Near-surface Retrieval of Air Temperature and Specific Humidity Using Multisensor Microwave Satellite Observations. J. Geophys. Res. 111, D10306, doi:10.1029/2005JD006431.

70. Béranger K., Barnier, B., Gulev, S. \& Crépon, M. (2006). Comparing Twenty Years of Precipitation Estimates from Different Sources Over the World Ocean. Ocean Dyn. 56(2), 104-138, doi:10.1007/s10236-006-0065-2.

71. Gille, S. \& Co-Authors (2010). Surface Fluxes in High Latitude Regions. In these proceedings (Annex).

72. Send, U. \& Co-Authors (2010). OceanSITES. In these proceedings (Vol. 2), doi:10.5270/OceanObs09.cwp.79.

73. Kaplan, A., Cane, M.A. \& Arnold, N.P. (2009). Error Models for Sea Surface Height Data from Altimetry-based Products. JCSDA 7th Workshop on Satellite Data Assimilation, May 2- 13, 2009, available at http://www.jcsda.noaa.gov/documents/meetings/wk shp2009/Session-2b/5.Oral-Alexey.Kaplan.ppt

74. Richman, J. G. \& Miller, R.N. (2010). Model Representation Error Estimation for Ocean Data Assimilation. Ocean Model. (submitted).

75. Berry, D.I. \& Kent, E.C. (2009). A New Air-Sea Interaction Gridded Dataset from ICOADS with Uncertainty Estimates. Bull. Amer. Meteor. Soc. 90, 645-656.

76. Maes C., Behringer, D., Reynolds, R.W. \& Ji, M. (2000). Retrospective Analysis of the Salinity Variability in the Western Tropical Pacific Ocean Using an Indirect Minimization Approach. $J$. Atmos. Oceanic Technol. 17, 512-524.

77. Fujii, Y. \& Kamachi, M. (2003). Three Dimensional Analysis of Temperature and Salinity in the Equatorial Pacific Using a Variational Method with Vertical Coupled Temperature-salinity EOF Modes. J. Geophys. Res. 108(C9), 3297, doi:10.1029/2002JC001745.

78. Testut C.-E., Brasseur, P., Brankart, J.-M. \& Verron, J. (2003). Assimilation of Sea-surface Temperature and Altimetric Observations During 1992-1993 into an Eddy Permitting Primitive Equation Model of the North Atlantic Ocean. J. Mar. Syst. 40-41, 291-316.

79. Usui, N., Ishizaki, S., Fujii, Y., Tsujino, H., Yasuda, T. \& Kamachi, M. (2006). Meteorological Research Institute Multivariate Ocean Variational 
Estimation (MOVE) System: Some Early Results. Adv. Spa. Res. 37, 806-822.

80. Fukumori, I. (2002). A Partitioned Kalman Filter and Smoother. Mon. Wea. Rev. 130, 1370-1383.

81. Zhang, S., Harrison, M.J., Rosati, A. \& Wittenberg, A. (2007). System Design and Evaluation of Coupled Ensemble Data Assimilation for Global Oceanic Studies. Mon. Wea. Rev. 135, 3541-3564.

82. Keppenne, C.L., Rienecker, M.M., Jacob, J.P. \& Kovach, R. (2008). Error Covariance Modeling in the GMAO Ocean Ensemble Kalman Filter. Mon. Wea. Rev. 136, 2964-2982, doi:10.1175/2007MWR2243.1.

83. Yang, S.-C., Keppenne, C., Rienecker, M. \& Kalnay, E. (2009). Application of Coupled Bred Vectors to Seasonal-to-Interannual Forecasting and Ocean Data Assimilation. J. Clim. 22, 2850-2870.

84. Yang, S.-C., Rienecker, M. \& Keppenne, C. (2010). The Impact of Ocean Data Assimilation on Seasonal-to-Interannual Forecasts: A case study of the 2006 El Niño Event. J. Clim. 23, 4080-4095.

85. Balmaseda, M., Anderson, D. \& Vidard, A. (2007). Impact of Argo on Analyses of the Global Ocean. Geophys. Res. Lett. 34, L16605, doi:10.1029/2007GL030452.

86. Haines K. \& Co-Authors (2006). Salinity Assimilation Using $S(T)$ : Covariance Relationships. Mon. Wea. Rev. 134, 759-771.

87. Smith G.C. \& Haines, K. (2009). Evaluation of the $S(T)$ Assimilation Method with the Argo Dataset. Q. J. Roy. Meteorol. Soc. 135, 739-756.

88. Hurlburt, H.E. \& Co-Authors (2009). Highresolution Global and Basin-scale Ocean Analyses and Forecasts. Oceanography, 22 (3), 110-127.

89. Lagerloef, G. \& Co-Authors (2010). Resolving the Global Surface Salinity Field and Variations by Blending Satellite and In Situ Observations. In these proceedings (Vol. 2), doi:10.5270/OceanObs09.cwp.51.

90. Sugiura, N. \& Co-Authors (2008). Development of a Four-dimensional Variational Coupled Data Assimilation System for Enhanced Analysis and Prediction of Seasonal to Interannual Climate Variations, J. Geophys. Res. 113, C10017, doi:10.1029/2008JC004741.

91. Fujii, Y., Nakaegawa, T., Matsumoto, S., Yasuda, T., Yamanaka, G. \& Kamachi, M. (2009). Coupled Climate Simulation by Constraining Ocean Fields in a Coupled Model with Ocean Data. J. Clim. 22, 5541-5557.
92. Breivik, L. \& Co-Authors (2010). Remote Sensing of Sea Ice. In these proceedings (Vol. 2), doi:10.5270/OceanObs09.cwp.11.

93. Lisæter, K. A., Rosanova, J. \& Evensen, G. (2003). Assimilation of Ice Concentration in a Coupled IceOcean Model using the Ensemble Kalman Filter. Ocean Dynam. 53, 368-388.

94. Caya, A., Buehner, M. \& Carrieres, T. (2010). Analysis and Forecasting of Sea Ice Conditions with Three-dimensional Variational Data Assimilation and a Coupled Ice-Ocean Model. $J$. Atmos. Oceanic Tech. 27, 353-369.

95. Brasseur, P. \& Co-Authors (2009). Integrating Biogeochemistry and Ecology into Ocean Data Assimilation Systems. Oceanography, 22 (3), 206215.

96. Berline, L., Brankart, J.M., Brasseur, P., Ourmières, Y. \& Verron, J. (2007). Improving the Dynamics of a Coupled Physical-Biogeochemical Model of the North Atlantic Basin Through Data Assimilation: Impact on Biological Tracers. J. Mar. Syst., 64, 153-172.

97. Ourmières Y., Brasseur, P., Lévy, M., Brankart, J.M. \& Verron, J. (2009). On the Key Role of Nutrient Data to Constrain a Coupled PhysicalBiogeochemical Assimilative Model of the North Atlantic Ocean. J. Mar. Syst. 75, 100-115. doi:10.1016/j.jmarsys.2008.08.003.

98. Nerger, L. \& Gregg, W.W. (2007). Assimilation of SeaWiFS data into a Global Ocean-Biogeochemical Model Using a Local SEIK filter. J. Mar. Syst. 68, 237-254.

99. Gregg, W.W. (2008) Assimilation of SeaWiFS Ocean Chlorophyll Data into a Three-dimensional Global Ocean Model. J. Mar. Syst. 69, 205-225.

100. Oke, P.R. \& Co-Authors (2010). Ocean Observing System Evaluation. In these proceedings (Vol. 2), doi:10.5270/OceanObs09.cwp.67.

101. Guinehut, S., Le Traon, P.-Y., Larnicol, G. \& Phillips, S. (2004). Combining Argo and Remotesensing Data to Estimate the Ocean Threedimensional Temperature Fields - A First Approach Based on Simulated Observations. $J$. Mar. Syst. 46, 85-98.

102. Pascual, A., Faugère, Y., Larnicol, G. \& Le Traon, P.-Y. (2006). Improved Description of the Ocean Mesoscale Variability by Combining Four Satellite Altimeters. Geophys. Res. Lett. 33, doi:10.1029/2005 GL024633.

103. Pascual, A., Boone, C., Larnicol, G. \& Le Traon, P.-Y. (2009). On the Quality of Real Time Altimeter Gridded Fields: Comparison with In Situ 
Data. J. Atmos. Ocean. Tech. 26, 556-569, doi:10.1175/2008JTECHO556.

104. Tranchant, B., Testut, C.E., Renault, L., Ferry, N., Birol, F. \& Brasseur, P. (2008). Expected Impact of the Future SMOS and Aquarius Ocean Surface Salinity Missions in the Mercator Ocean Operational Systems: New Perspectives to Monitor Ocean Circulation. Rem. Sens. Env. 112, 14761487.

105. Brassington, G. B. \& Divakaran, P. (2009). The Theoretical Impact of Remotely Sensed Sea Surface Salinity Observations in a Multi-variate Assimilation System. Ocean Model. 27, 70-81.

106. Stammer, D., Köhl, A. \& Wunsch, C. (2007). Impact of the GRACE Geoid on Ocean Circulation Estimates. J. Atmos. Ocean. Technol. 24, 14641478.

107. Baehr, J., McInerney, D., Keller, K. \& Marotzke, J. (2008). Optimization of an Observing System Design for the North Atlantic Meridional Overturning Circulation, J. Atmos. Oceanic Technol. 25, 625-634.

108. Forget, G., Ferron, B. \& Mercier, H. (2008). Combining Argo Profiles with a General Circulation Model in the North Atlantic. Part 1: Estimation of Hydrographic and Circulation Anomalies from Synthetic Profiles, Over a Year. Ocean Model. 20, 1-16.

109. Langland, R. H. \& Baker, N.L. (2004). Estimation of Observation Impact using the NRL Atmospheric Variational Data Assimilation Adjoint System. Tellus 56A, 189-201.

110. Gelaro, R. \& Zhu, Y. (2009). Examination of Observation Impacts Derived from Observing System Experiments (OSEs) and Adjoint Models, Tellus A 61, 179-193. 